\title{
Lo que "significa" el castillo de Turégano (Segovia, España): Un ensayo metodológico entre diacronía y sintaxis espacial
}

\section{The "significance" of Turégano castle (Segovia, Spain): A methodological essay between diachrony and space syntax}

\author{
Jordi A. López Lillo ${ }^{1}$ \\ Instituto de Ciencias del Patrimonio (Incipit-CSIC)
}

\begin{abstract}
RESUMEN
El castillo de San Miguel Arcángel constituye un edificio verdaderamente singular no solo por los debates generados en torno a las complejidades de su secuencia constructiva, resultado de la fortificación de una iglesia románica, sino, en parte explicando tal complejidad, porque Turégano ejerció como cabecera del señorío episcopal de Segovia cuando desempeñaba su papel más crucial en la historia del Reino de Castilla (ss. XIII-XV). Este trabajo persigue abordar su interpretación desde la perspectiva de la producción de significados no discursivos en su estructura espacial mediante la aplicación de una metodología relativamente novedosa; o al menos, poco explotada en el análisis arqueológico de este tipo de edificios. Para ese fin, será necesario ensayar una restitución hipotética de las condiciones originales del castillo, permitiendo así retroalimentar experimentalmente lo extraído de su sintaxis espacial y de una lectura estratigráfica indiciaria que por lo pronto revela varios procesos de fortificación superpuestos.
\end{abstract}

Palabras clave: Arquitectura militar; iglesia encastillada; Edad Media; agencia; identidad social.

\section{ABSTRACT}

The castle of San Miguel Arcángel is a very unique building not only because of the debates on its complex building process, resulted from fortifying a Romanesque church, but also because Turégano was the seat of the Segovia Bishop's domains in a time when this diocese played a crucial role in the history of the Kingdom of Castile (13th-15th centuries). This paper deals with the interpretation of such a building by focusing on the production of non-discursive meanings in its spatial structure by applying a fairly innovative methodology or, at least, little exploited for the archaeological analysis of this type of constructions. In order to do so, a hypothetical restoration of the original conditions of the castle will be necessary, making this possible to lead to an experimental feedback between the results of space syntax analyses and an even tentative stratigraphic reading, which indeed reveals more than one fortification process.

Key words: military architecture; fortified church; Middle Ages; agency; social identity.

Recibido: 14-04-2020. Aceptado: 28-05-2020. Publicado online: 19-11-2020

Cómo citar este artículo / Citation

López Lillo, J. A. 2020: "Lo que «significa» el castillo de Turégano (Segovia, España): Un ensayo metodológico entre diacronía y sintaxis espacial", Arqueología de la Arquitectura, 17: e099. https://doi.org/10.3989/arq.arqt.2020.008

Copyright: (c) CSIC, 2020. (c) UPV/EHU Press, 2020. Este es un artículo de acceso abierto distribuido bajo los términos de la licencia de uso y distribución Creative Commons Reconocimiento 4.0 Internacional (CC BY 4.0). 
No hace mucho, Jesús Bermejo Tirado introducía un monográfico dedicado a la sintaxis espacial precisamente en Arqueología de la Arquitectura comentando cómo el nivel de abstracción de estas herramientas ha derivado en un "cierto ánimo pedagógico" reflejado en apartados introductorios que constituyen verdaderas síntesis omnicomprensivas de los principios en que se funda la metodología (Bermejo 2015). Mi intención aquí no será profundizar tanto, entre otras cosas porque tengo la suerte de poder remitir a esos textos para aquellos aspectos que escapen al interés inmediato de este ensayo. Pueden consultarse en castellano el trabajo pionero de Julia Sánchez (1998) o, por supuesto, algunos de los firmados por el propio Bermejo (2009, 2014), así como los contenidos en aquel monográfico y una larga lista de aplicaciones al registro arqueológico de casos de estudio concretos (Mañana et al. 2002; Vaquer y Nielsen 2011; Gutiérrez 2012; Gutiérrez y Grau 2013; Grau y Segura 2013; Salminci 2015).

El creciente interés que testimonian estos trabajos se justifica sin duda en el hecho de que, si la Arqueología se constituye como la disciplina del análisis de las culturas, sociedades e historias de los grupos humanos a través de su materialidad, la sintaxis espacial promete proporcionar una buena cantidad de "elementos distributivos" para la comprensión de las lógicas que estructuran unos entornos materiales -arquitectónicos en este caso- que en los últimos años venimos descubriendo como un agente social más operando en nuestros procesos de endoculturación (Olsen 2010; Preucel 2010; Hodder 2012), y no precisamente uno secundario. Otra cuestión es la interpretación que se haga de esas distribuciones; o más concretamente, la discusión sobre la solvencia de unas u otras teorías de interpretación.

Por supuesto, la idea no es nueva. Ya la proxémica de Edward T. Hall $(1990,2003)$ advertía a mediados del pasado siglo -y empezaba por remitir nada menos que a Franz Boas, todavía cincuenta años anterior- que el espacio no es un mero producto artefactual, sino que comunica "patrones culturales" tan efectivamente que genera respuestas precisas y tangibles en la conducta de unos individuos no siempre apercibidos del condicionamiento. Su concepción de la cultura humana como un fenómeno caracterizado por la comunicación, ejecutada en diferentes niveles de consciencia simultáneos, la situaba explícitamente mediando nuestras relaciones con todo lo que nos rodea "en un moldeamiento mutuo". E independientemente de sus carencias, quizá lo más interesante es que Hall planteara esto en un tono etológico que haríamos bien en rescatar si queremos comenzar a recomponer sinceramente la fractura del paradigma disciplinar por donde se pierden esas discusiones; por más que puestos a comenzar, como tantos otros, tampoco él alcanzara a establecer con rotundidad hasta qué punto esa dicotomía naturaleza-cultura es de hecho un dispositivo característico de nuestras culturas en sus procesos de adaptación a un medioambiente que es también la propia cultura. Cómo la semiosis cultural no nos distancia de lo biológico, sino que revela y vertebra la biología de la humanidad en tanto especie natural.

En cualquier caso, de aquí en adelante el camino intelectual es evidente, jalonado de autores de quienes no se puede prescindir: Clifford Geertz (2005) y su definición del "animal inserto en tramas de significación"; Marshall Sahlins (2008) o Pierre Bourdieu (2008, 2012) y las "estructuras estructuradas con capacidad de estructuras estructurantes", salvando en el trabalenguas la oposición entre aproximaciones holistas e individualistas; Amos Rapoport $(1990,1993)$ traduciendo todo esto a los términos de la Arquitectura, cuando menos para ser empleado en tales términos por el resto de disciplinas sociológicas. Pero ya basta.

En una de las encrucijadas de ese recorrido, los arquitectos del UCL Bill Hillier y Julienne Hanson plantearon que, si los modos de habitar el espacio son también modos de segmentar y procesar el continuo de lo real en términos culturalmente significativos, como sucede con toda comunicación, debía de poderse ensayar un análisis sistémico enfocado a las estructuras no discursivas de carácter matemático que subyacen en esta "semántica" (Hillier y Hanson 1984; Hanson 2003). Así, su programa para lo que denominaron "sintaxis espacial" perseguía identificar los objetos y relaciones irreductibles del sistema de comunicación, diseñar modos de representarlos ideográficamente, y examinar las maneras en las que se combinan entre ellos formando estructuras más complejas y regularidades a las que primero se referirían como "patrones" y, más adelante, en un intento por dotar de mayor fluidez al término, sencillamente como "configuraciones" (Hillier 2007).

El objetivo de este ensayo, cuya toma de datos se realizó en el marco de un estudio mayor promovido por el Ayuntamiento de Turégano y ejecutado por Caminos del Románico², es el de explorar las posibilidades y limitaciones de las técnicas englobadas bajo esta denominación

\footnotetext{
Concretamente, los trabajos de campo principales se condujeron entre junio y julio de 2018 centrándose en la lectura de paramentos del interior del edificio principal, previa autorización de la Comisión Territorial de Patrimonio Cultural de la Junta de Castilla y León (Exp. Núm.: RH-38/2018-10). Participamos, Isaac Sastre de Diego, L. Miguel Yuste Burgos, Gonzalo Moyano y yo mismo; a quienes cabría sumar al menos a Carlos de Miguel Calvo y a Débora M. Kiss para el desarrollo de partes específicas de una publicación monográfica todavía en preparación.
} 
a la hora de interpretar un conjunto arquitectónico especialmente complejo. Es evidente que la aproximación a las lógicas de estructuración social del espacio que entrañaba el diseño original de la fortificación a examen está supeditada a la comprensión de la particular biografía del edificio, y en este sentido, se pretende específicamente evaluar la puesta en relación del enfoque sintáctico con la estratigrafía indiciaria que puede rastrearse a través de los cuerpos de obra visibles en la actualidad, a la espera de una lectura de paramentos más exhaustiva. Evaluar, en suma, su retroalimentación en aquellas partes de la secuencia constructiva más problemáticas.

En cualquier caso, la propia implementación de ese enfoque sintáctico en el análisis castellológico cuenta con muy escasos precedentes. Esto define hasta cierto punto el carácter exploratorio del ensayo; pero, sobre todo, convierte en fundamental el recurso al trabajo de la arqueóloga neerlandesa Eva Mol (2012) sobre los castillos del Reino cruzado de Jerusalén (ss. XII-XIII), sin duda el exponente más completo y profundo publicado hasta la fecha. A este respecto, cabe aclarar que aunque es cierto que se tiene constancia de la "villa de Torodano" desde poco antes de 1123, cuando fue donada por la reina leonesa Urraca I y su hijo Alfonso VII al obispado de Segovia, el edificio conservado es con certeza muy posterior, y esto condiciona irremediablemente las comparaciones más directas con los resultados obtenidos por Mol. No obstante, tanto su planteamiento como su caracterización de "configuraciones genotípicas" distintivas entre castillos pertenecientes a órdenes religiosas y a nobleza secular van a aportar elementos para la reflexión más que significativos.

\section{UN POCO, PERO SOLO UN POCO, DE MATEMÁTICAS}

De las varias técnicas desarrolladas a partir de la propuesta de Hillier y Hanson, una de las que ha alcanzado mayor predicamento concretamente en el estudio de edificaciones -es decir: en su estudio al margen del contexto, igualmente edificado o no, en el que se inscribieren- es el llamado "análisis gamma" o de accesibilidad. Es también el que vertebra la mayoría de trabajos, y este no será una excepción, por lo que conviene detenerse en sus fundamentos.

La clave conceptual aquí es la dualidad de la idea de límite, que "de una vez y al tiempo genera una categoría de espacio -el interior- y una forma de control -el límite en sí mismo-" (Hillier y Hanson 1984: 146). Ello lo convierte en uno de los puntos donde el vínculo entre la espacialidad y ciertos dispositivos culturales básicos para orientar las conductas sociales se hace más evidente, no solo determinándose mutuamente las condiciones del estar dentro o fuera y las identidades del ser nosotros o los otros, sino anunciando además una tercera identificación a la que vengo refiriéndome como la de "los otros nosotros" (López 2019), indispensable para esos procesos de orientación situacional aunque se la haya disuelto habitualmente entre las estrecheces dicotómicas de muchas tradiciones interpretativas:

Todo edificio selecciona dentro del conjunto de extraños un subconjunto de "visitantes", que son personas que pueden ingresar temporalmente al mismo, pero no controlarlo [...]. Un edificio puede entonces definirse de manera abstracta como un cierto ordenamiento de categorías al cual se añade un cierto sistema de controles, construyendo entre ambos un interfaz entre los habitantes del dominio social inscrito en esas categorías y los visitantes, cuyas relaciones con los antedichos controla (Hillier y Hanson 1984: 146-147).

El análisis de accesibilidad es por tanto, en esencia, una descripción matemática de la permeabilidad topológica de los espacios discretos en que se divide un edificio. Su representación en forma de grafo los presenta como nodos interconectados y "justificados" según su profundidad dentro del sistema. Es decir: según el número mínimo de otros espacios que es necesario atravesar para alcanzarlos partiendo de un "nodo raíz" que suele establecerse en el exterior por defecto, aunque pueda variarse según lo que se pretenda analizar.

Dadas tales premisas, el análisis se centra básicamente en dos medidas. Por un lado, la integración del sistema se expresa a través del cálculo de la "asimetría relativa" de sus espacios en comparación con la profundidad-superficialidad potencial de ese sistema en esos espacios si todos estuvieran conectados a la raíz o si, por contra, se organizaran linealmente; de ahí la fórmula $\mathrm{RA}=2(\mathrm{MD}-1) /{ }_{\mathrm{k}-2}$, donde $k$ equivale al número de nodos del sistema y MD a la profundidad media del espacio en cuestión, calculada a su vez dividiendo entre $k-l$ la suma de las distancias mínimas entre ese espacio y todos los demás. Esto arroja una cifra entre 0 y 1 , siendo los valores bajos espacios donde el sistema es más superficial y tiende a integrarse, y lo contrario, espacios más bien segregados. Sin embargo, aunque no afecta a su distribución sintáctica, el tamaño del sistema analizado influye considerablemente en las cifras obtenidas. Por 
eso cuando - como será el caso aquí- lo que se pretende es comparar sistemas diferentes, ha de realizarse todavía una corrección que pondere realmente la asimetría relativa de cada uno de estos espacios dividiéndola entre un "valor D" que corresponde a la asimetría relativa del nodo raíz de un sistema hipotético en forma de diamante en cuya profundidad media hubiera tantos nodos como nodos tenga el sistema que se quiere corregir; o expresado matemáticamente: $\mathrm{RRA}=\mathrm{RA} /{ }_{\mathrm{Dk}}$, donde los valores obtenidos siguen la misma lógica interpretativa pero ya no se limitan al rango entre 0 y 1 .

La segunda medida básica es el denominado "valor de control" (CV), que ya no expresa términos globales como hace el cálculo de la integración, sino que relaciona localmente un espacio dado con sus vecinos inmediatos con el fin de determinar su posición respecto a la distribución de la permeabilidad. Así, considerando que cada espacio es un entero que se reparte entre sus vecinos en proporción al número de estos, el $\mathrm{CV}$ de un nodo equivale a la suma de las fracciones recibidas, siendo que valores por debajo de 1 representan puntos significativamente controlados dentro del sistema de circulación mientras que las cifras por encima tienden a lo opuesto, y por tanto corresponden a espacios distribuidores.

\section{UN CASTILLO QUE NO ES PROPIAMENTE UN CASTILLO: INTRODUCCIÓN AL CASO DE ESTUDIO}

Hay muchas cosas que hacen del de Turégano un castillo verdaderamente particular, pero solo una es visible del otro lado del arroyo que lo separa del casco urbano: una enorme espadaña descollando por encima del conjunto, añadida en 1703 , cuando hacía ya mucho tiempo que cualquier proyección militar se había restringido a la de cárcel del reino (Fig. 1). De no ser por ella, su apariencia sería la típica de las fortificaciones preabaluartadas de transición que proliferaron a partir de mediados del $\mathrm{s}$. XV como primera respuesta al creciente empleo de armamento pirobalístico (Mora-Figueroa 1993); con una falsabraga rectangular rematada por cuatro cubos a los que se añaden un par más pequeños flanqueando sendos accesos en las esquinas noroeste -hoy cegado- y sureste, precedida de un foso seco directamente tallado en la roca que de algún modo minimiza el blanco al "enterrar" ligeramente su aproche septentrional, y sobre cuyo perfil sobresale no obstante el edificio principal reforzado por hasta seis borjes y, sobre todo, la imponente triple torre del homenaje, de ángulos redondeados. Plagado todo de troneras de palo y orbe o cruz y orbe. Me atrevería

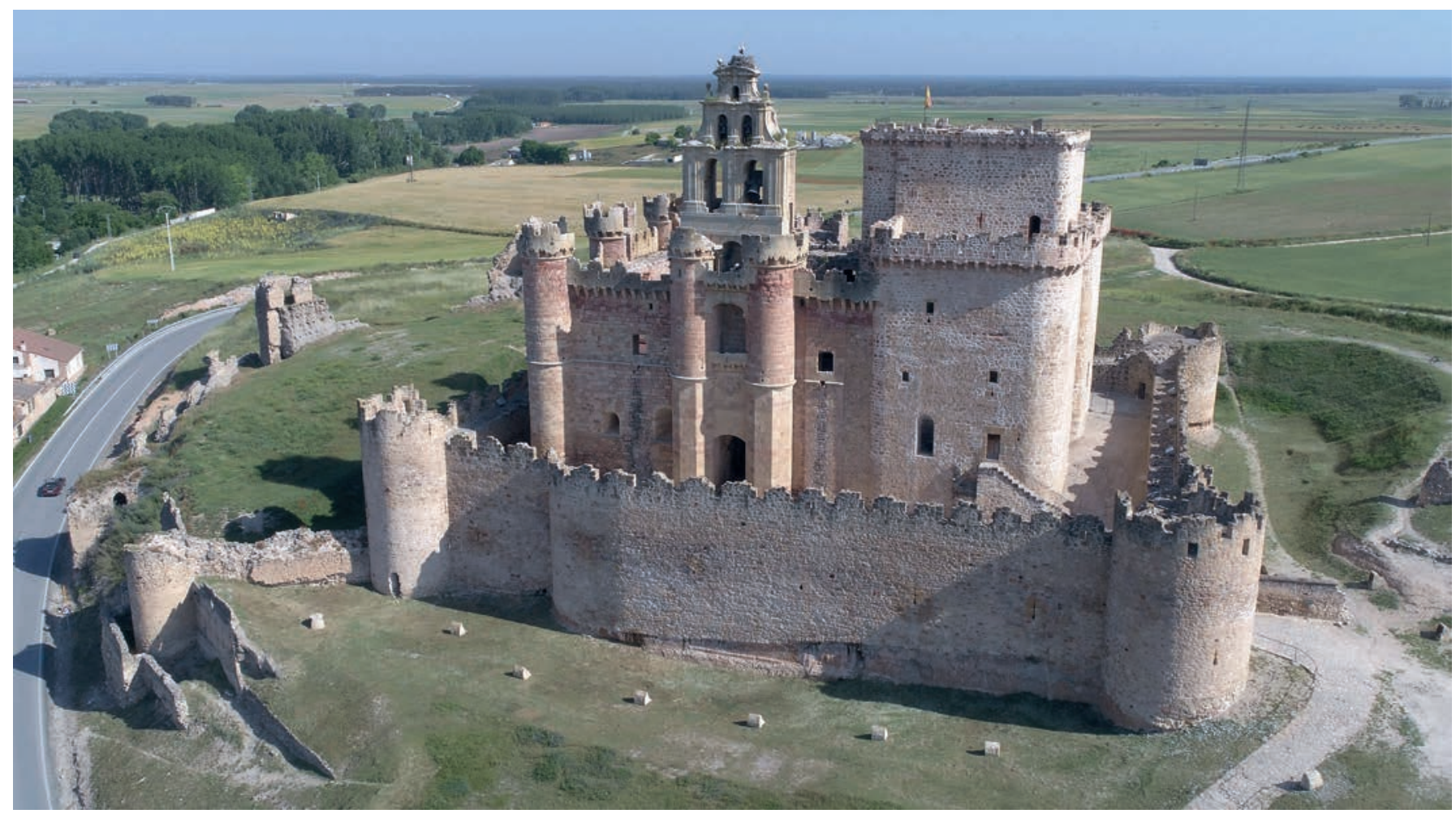

Figura 1. Vista aérea del conjunto arquitectónico desde el sur, rodeado por las ruinas de la cerca exterior a las que le une una coracha en primer plano (izquierda). Fotografía de Carlos Puerto. 
a decir incluso que recuerda a aquellos castillos de la Escuela de Valladolid (Cobos y Castro 1990) que se han tenido por simbólicos más que militarmente útiles, mera expresión del poder de sus dueños.

Esa "utilidad" también se ha cuestionado en el caso de Turégano, a pesar del consenso que apunta a que el planteamiento del edificio que vemos hoy -no así su finalización- correspondió al controvertido Juan Arias Dávila, abiertamente enfrentado al rey Enrique IV en vísperas de la guerra de sucesión castellana. Un documento fechado en 1471 lo atestigua al dejar constancia del acuerdo entre el obispo y los concejos de Turégano y Veganzones de destinar determinadas sisas "para una barrera que se ha de faser en derredor de la iglesia de Sant Miguel e para enforrar e alçar la dicha iglesia con sus bóvedas e faser en ella escaleras [para subir a la] torre de omenaje" (Yuste 2017: 127). Luego el castillo no es propiamente un castillo sino una iglesia encastillada (Bango 1997-1998; Dimanuel 2009; Arrieta 2012), y hete aquí el porqué de la españada. Se alude también allí a unos muros que debían derribarse, interpretados como las ruinas de una cerca exterior que todavía rodea a cierta distancia el conjunto, aparentemente levantada entre finales del s. XII y la primera mitad del XIII. ${ }^{3} \mathrm{Y}$ hasta ahí los consensos.

Es verdad que la discusión académica no se ha ocupado tanto de la fortificación como del proceso de construcción del templo, quizá porque en ella solo destaca a primera vista la diferencia de aparejo entre torre del homenaje y falsabraga, resueltas en mampostería, y ese "enforrado", que combina sillería y sillarejos trabados con ripio, mientras que entre la degradación generalizada del interior de la iglesia un sinfín de restos de revocos, parches, roturas y disonancias estilísticas dan cuenta vívidamente del ajetreo de su existencia. Por lo demás, responde a un diseño basilical distribuido en aula de tres naves, divididas a su vez en cuatro tramos a partir de un transepto no acusado en planta.

Son las cabeceras, rematadas en ábsides escalonados, las que soportan aquella triple torre del homenaje; circunstancia que, sumada a varias anomalías especialmente notorias en el encaje de la bóveda de la nave central con

\footnotetext{
3 Así se recoge en el informe técnico de las excavaciones realizadas por Aratikos Arqueólogos en 2005 [en línea]: https://aratikos.com/docftp/2005_Excavacion_en_el_recinto_amurallado_de_Turegano_Segovia.pdf [consultado el 30/03/2020]. Cabe añadir que se menciona también aquí una reforma de las torres -cuadrangulares- de este recinto fechada en la segunda mitad del s. XV, si bien los criterios que sustentan tal afirmación no quedan muy claros y me parece que en las siguientes páginas aflorarán razones para considerar que, de vincularse con algún proyecto de fortificación del edificio principal, no fuera precisamente con el último.
}

el crucero, llevó a algunos autores a aventurar que el origen del edificio pudo ser una capilla aislada, o incluso que fue la iglesia la que terminó de construirse dentro del patio de armas del castillo (Ruiz Montejo 1988). Otros se han apoyado en criterios artísticos no siempre bien entendidos para proponer fases en mayor o menor medida distantes entre sí (Borreguero 1991; Bermúdez y Marqués 2016), aunque Placido Centeno Roldán (1974), quien fue párroco del lugar hacia mediados del pasado siglo $-\mathrm{y}$ lo llenó de calicatas buscando entenderlo-, ya concluyó que obedecía a un proyecto unitario del cual se ha defendido que cuadra plenamente con las lógicas constructivas del románico (Rodríguez 2007). En ellas son recurrentes los "cambios sobre la marcha", que en este caso y tras una lectura de paramentos detallada (López y Yuste e. p.), parecen explicarse precisamente en relación con un proyecto de fortificación anterior al conservado, en un sentido para el cual existen paralelos arqueológicos recientes en la misma Extremadura castellana (Moreno y Murillo 2014). No por nada fue también Centeno uno de los primeros en referirse a los restos de un recrecido del perfil de la iglesia que la habría transformado en "casa fuerte", y en asociar a este momento el volteado de sendas cámaras infrapuestas a las bóvedas de la cabecera de las naves laterales, perforadas para darles acceso desde arriba, tradicionalmente interpretadas como graneros a pesar de la presencia de buhederas y -aquí sí- saeteras dirigidas al interior del templo. De hecho, hay suficientes indicios documentales como para sospechar que Turégano disponía de elementos defensivos relativamente importantes al menos desde el s. XIV, cuando se traslada allí la residencia episcopal habitual y acoge con frecuencia al rey y la corte, instalándose incluso la Chancillería Real antes de fijarse definitivamente en Valladolid; aunque las fuentes no aluden explícitamente a ellos; ni menos aun a su fisonomía.

\section{UN PUNTO DE PARTIDA EN LA EXPERIMENTACIÓN ACTUAL DEL EDIFICIO}

Cualquier realización práctica de una metodología comporta ciertas indeterminaciones, de las cuales aquellas conocidas deberían referirse, siempre, como principio. En el caso de la sintaxis espacial aplicada a la Arqueología la lista de problemas de medición suele encabezarla la falta de alzados, pero paradójicamente, aquí tal vez debería hacerlo su presencia. Más concretamente, la 
imposibilidad en las circunstancias actuales de desentrañar la parte de la estratigrafía que permanece oculta y de plantear otros procedimientos capaces de arrojar luz sobre cronologías, siquiera agrupando fuera de toda duda fases constructivas con base en la composición de sus materiales. Y aun el riesgo más importante sigue siendo olvidar que entre la última gran fase constructiva y la actualidad ha transcurrido cerca de medio milenio durante el cual el edificio continuó funcionando de una u otra manera, aunque solo sea evidente en lo que atañe al uso religioso. Sin embargo, nada es óbice para ensayar una aproximación a los términos efectivos de esa última fase partiendo del análisis de la situación actual, y aclarando quizá con ello algo de las que le precedieron.

Para ese ejercicio las planimetrías y alzados del Plan Director del Castillo de Turégano resultan hasta cierto punto insuficientes, sobre todo por la compleja articulación de los niveles de suelo, prácticamente independientes en cada una de las estancias de la torre del homenaje. Por esa misma razón, las técnicas basadas en áreas de visibilidad acaban siendo, además de harto difíciles, en buena medida irrelevantes, lo que ya es sintomático. En cuanto al análisis de accesibilidad, no ha habido otro remedio que sacrificar en algunas ocasiones el más estricto "criterio de convexidad" (vid. Bafta 2003) para priorizar la existencia de límites bien definidos en la asignación de determinados espacios: básicamente tramos de escalera, y básicamente a partir de la evidencia de antiguas puertas; a partir de la presencia de jambas y dinteles tallados y de huellas de quicios y trabas (Figs. 2-3). Dejando al margen la liza, la cual conviene mantener como exterior indiferenciado en una primera aproximación al edificio central con el fin de valorar un hipotético funcionamiento independiente, ese criterio arroja un total de 48 nodos correspondientes a estancias de diferente índole, escaleras, pasillos, terrazas y cámaras de tiro (Fig. 4). Destacan además ciertos espacios morfológicamente singulares, como son los "patios" del castillo habilitados sobre sendas naves laterales, el adarve que los perimetra, y por supuesto, la propia iglesia, que a efectos prácticos -y a día de hoy- se presenta más o menos diáfana a pesar de que todo indique que en tiempos estuvo compartimentada en algunos puntos que sin duda variaron diacrónicamente.

De hecho, como en general el nivel 1 del conjunto, el interior del templo es uno de los pocos lugares donde no solo es posible plantear un análisis de visibilidad sin mayores problemas, sino que sus resultados permiten comprender intuitivamente pero aun en términos sintácticos

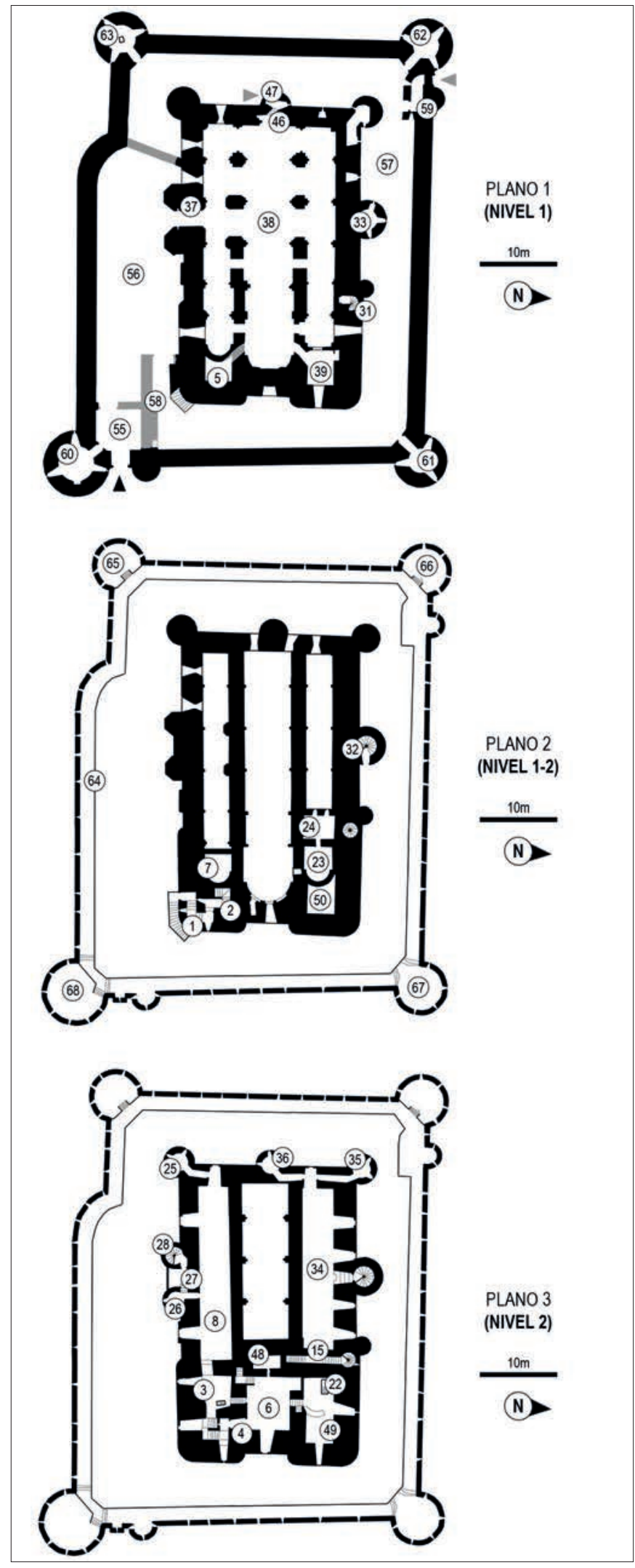

Figura 2. Distribución de los espacios actuales e hipotéticos analizados entre los niveles 1 y 2 del conjunto arquitectónico; elaboración propia a partir del Plan Director del Castillo de Turégano firmado por Alberto García Gil en 2007. 


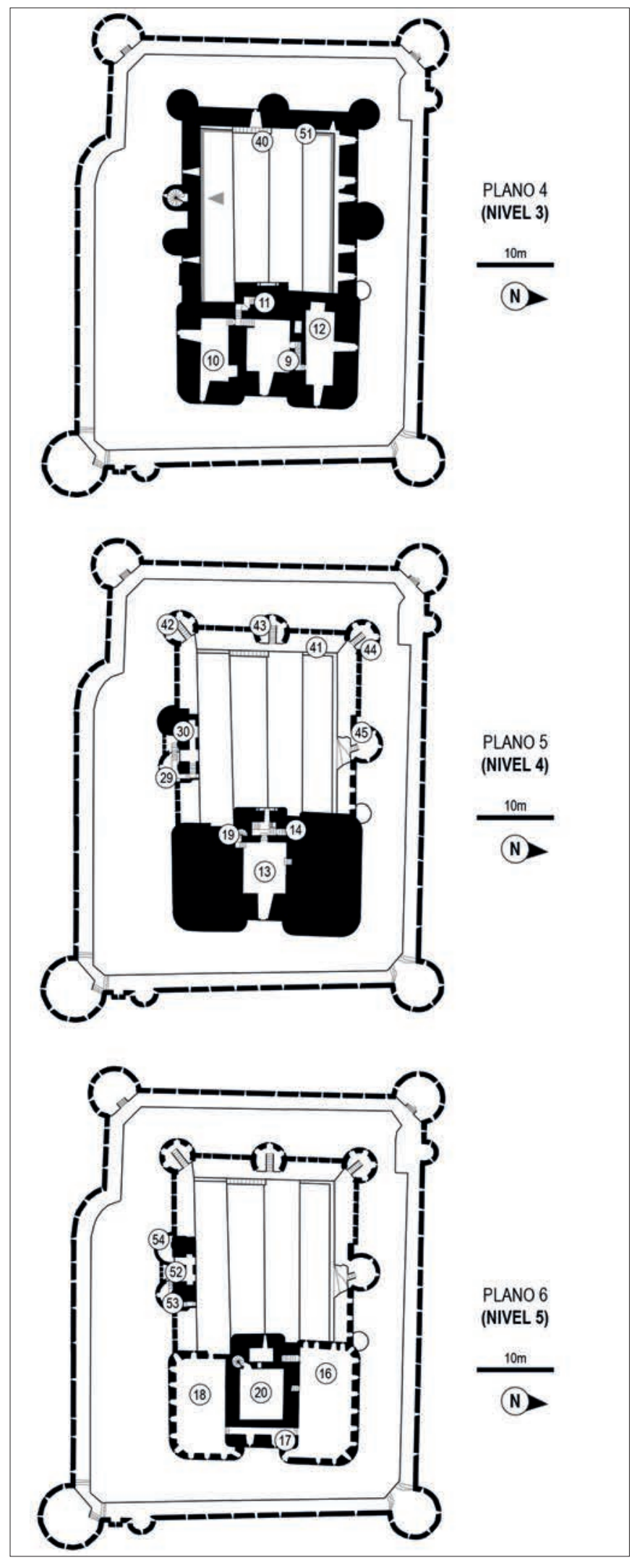

Figura 3. Distribución de los espacios actuales e hipotéticos analizados entre los niveles 3 y 5 del conjunto arquitectónico; elaboración propia a partir del Plan Director del Castillo de Turégano firmado por Alberto García Gil en 2007. la configuración interna de esas zonas singulares en tanto, como escriben Alasdair Turner et al. (2001: 103), esta técnica "proporciona una descripción del espacio 'desde dentro', desde el punto de vista de los individuos tal como lo perciben, interactúan con él y se mueven a su través". Fueron estos mismos autores quienes desarrollaron las clásicas "isovistas arquitectónicas" hacia un análisis capaz de ponderar simultáneamente parámetros locales y globales mediante un grafo de visibilidad basado en una malla ortogonal de "puntos de vista" cuya distancia suele ajustarse con base en la proxémica, a razón de un metro cada punto. Esto permite definir áreas de prominencia visual que, en el caso de la iglesia de San Miguel (Fig. 5), sobre certificar la segregación de los espacios 5, 39 y 47 -nótese que 46 no se comporta igual porque las puertas que lo definieron han desaparecido, y otro tanto podría decirse de 37-, diferencian el espacio 38 en sus tres naves y, sobre todo, en dos mitades. Así, la integración visual de las naves laterales en su mitad oriental es significativamente baja a causa de las reducciones de la luz de los arcos del primer tramo y el cegamiento de los del transepto, al menos las primeras probablemente dentro del programa de refuerzo derivado de la última fortificación. Aunque el patrón evidentemente no varíe, estas diferencias de prominencia en el interior de la iglesia se mitigan tan pronto se observan en el contexto mayor que delimita la falsabraga, donde destaca por encima de todo el corredor entre esta y la fachada principal de aquella. Y es que cabe tener en cuenta que, a efectos de experimentación sensorial, elementos como los pilares suponen al fin y al cabo trabas visuales fáciles de soslayar con desplazamientos relativamente cortos, resultando un espacio no estrictamente convexo, pero sí mucho más "contenido en sí mismo" que, sin ir más lejos, la liza.

En esta línea, el grafo de visibilidad proporciona a su vez la base para el denominado "análisis agente": la simulación computacional del movimiento pedestre en entornos construidos, especialmente cuando este se prevé más exploratorio que intencionalmente orientado, o donde población e intenciones son suficientemente variadas como para que el establecimiento apriorístico de parámetros de destino influya negativamente en la comprensión de la manera en que cada configuración espacial condiciona la circulación. Al contrario, estudios comparativos con patrones de movimiento documentados positivamente (Penn y Turner 2002; Turner y Penn 2002) sugieren que el mayor grado de correlación no se obtiene ni siquiera ponderando los modelos según el "coeficiente de agrupamiento" que mide -por así 
0 a Liza; hoy dia transitable como un único espacio perimetral de circunvalación entre edificio principal y falsabraga, si bien existen $1,32^{+}, 38,(47)^{+}$ 1 evidencias de segmentaciones anteriores, recogidas a nivel hipotético en los espacios 55 a 58 (vid. fig. 13)

$1 \quad$ Primera sección de escalera acodada en el ingreso a la torre del homenaje desde el sur, actualmente tras un patín que 0(64), 2 salva la altura del vano desde la liza

2 Secciones de escaleras acodadas el último tramo de las cuales guarda un muro con aspillera; frente a él, en una cota inferior, $1,3,4,(5)^{+}$ se abre al sur sin solución de continuidad una cámara de tiro con bancos adosados

3 Estancia en el nivel 2 de la torre sur accesible a mitad del espacio 2 a través de la rotura del recrecido del ábside, visible $2,6,7^{+}, 8$ gracias a una calicata que también ha dejado descubierta la huella del tejado de la iglesia; pese a estar revocados y, probablemente, ensanchados, parece que tanto este acceso como el que se hacia el patio sur -cerca de donde se aprencian algunas piezas careadas- formaron parte del proyecto original

$4 \quad$ Pasillo que conecta las torres sur y central por el nivel2

$5 \quad$ Pequeña estancia en el nivel 1 de la torre sur, entre el paramento exterior del ábside y el interior de la torre del homenaje; (2)+, 38* actualmente cuenta con un acceso desde la iglesia -que rompe toscamente ese ábside-, si bien una abertura bien escuadrada pero cegada por una serie de lajas denotan un antiguo acceso vertical

6 Estancia en el nivel 2 de la torre central que cuenta con chimenea en el extremo noroeste, dentro de la cual puede 4, 3, 9, 10, 11, apreciarse la huella del recrecido del ábside; es igualmente visible, al oeste, parte de la ventana oriental del antiguo $48^{+*}$ campanario de la iglesia sobre la que se han practicado dos cerramientos sucesivos en ladrillo macizo y mampostería y, por debajo, en la obra de sillería románica, un pequeño agujero da acceso mediante escala portátil al espacio 48; en la pared contraria a la chimenea se levanta un murete alineado con ella que cubre el paso hacia 10 y 11

$7 \quad$ Estancia bajo la bóveda de presbiterio y ábside sur de la iglesia ganada mediante la interposición de una segunda bóveda $3^{+}$ de menor altura; el muro que la cierra por el oeste aparece actualmente rehecho en ladrillo hueco

8 Patio sur; espacio sin techar sobre la cubierta de la nave sur de la iglesia, en los revocos de cuyos paramentos meridional 3, 25, 26, 40+* y oriental se aprecian huellas de estructuras de compartimentación hoy desaparecidas

9 Sistema de escaleras en forma de "t" que conecta la torre central con la norte en los niveles 2 y 3

$12,6,22 \quad 3,4$

10 Estancia en el nivel 3 de la torre sur; cuenta con una chimenea descentrada en su extremo oriental cuyo tiro alcanza la 6 terraza central, mientras que en el extremo contrario se conecta axialmente con el espacio 6 salvando los mismos peldaños que conducen, girando al oeste, hacia el 11

11 Sistema de escalera acodada y rellano de distribución que se introduce en el antiguo campanario por su ventana $6,13,14,15^{+*}$ meridional; un agujero en la esquina noroeste permite el acceso al espacio 15, en el descenso hacia el cual puede constatarse la potencia del macizado que recrece la cota de suelo desde el románico hasta el actual

12 Estancia en el nivel 3 de la torre norte; cuenta con una chimenea al oeste alineada con el eje longitudinal, cuyo tiro alcanza 9 únicamente la terraza de su misma torre

13 Estancia en el nivel 4 de la torre central a la que se accede desde el rellano de 11 salvando unos escalones que cruzan la 11, 16, 19 ventana oriental del antiguo campanario nuevamente hacia lo que fue el exterior, siendo visibles aun algunas dovelas

14 Sección recta de escalera que dispuso de puertas en ambos extremos 5,6

15 Escalera rampante presumiblemente dispuesta sobre la cubierta de la nave norte y el hombro de la central hasta alcanzar el $11^{+*}, 31$ nivel de suelo del campanario, cubierta a lo largo de su recorrido por varios tramos de bóveda con señales de haber sido rehechos; los umbrales de sendos extremos presentan jambas y dinteles tallados

\begin{tabular}{|llll}
\hline 16 & Terraza de la torre norte & 6 \\
\hline 17 & Pasillo flanquedado por rastrillos que comunica las terrazas de las torres norte y sur, atravesando a cota del nivel 5 la torre & $16,13,14$
\end{tabular}
central por su extremo oriental

18 Terraza de la torre sur 6

19 Escalera de husillo que comunica los niveles 4,5 y 6 de la torre central, dispuesta en su ángulo suroeste

$13,20,21 \quad 5,6$

20 Estancia en el nivel 5 de la torre central; además de los vanos, definen su nivel de suelo -actualmente restaurado en 19 madera- sendas líneas de mechinales en los paramentos septentrional y meridiona

21 Terraza de la torre central; nótese que no aparece consignada en los planos, siendo el único espacio del nivel 6

19

22 Estancia en el nivel 2 de la torre norte; aunque hoy día aparece como un espacio cuyo volumen oriental desciende hasta el $9,23^{+},(49)$ nivel 1-2 revelando entremedias la cornisa del ábside septentrional de la iglesia, la huella de un recrecido de ese ábside en buena parte de la bóveda actual así como sendas líneas de mechinales en los muros septentrional y meridional de esta parte a cota del suelo de la mitad occidental hacen pensar que estuvo compartimentado según se reflefa hipotéticamente con los espacios 49 y 50 (vid. fig. 13)

23 Estancia bajo la bóveda de presbiterio y ábside norte de la iglesia ganada mediante la interposición de una segunda $22^{+}, 24$ bóveda de menor altura

24 Estancia bajo la bóveda del transepto norte de la iglesia ganada mediante la interposición de una segunda bóveda de 23 menor altura; además de una buhedera, conserva dos saeteras hoy cegadas en el muro que la cierra occidentalmente

Figura 4. Listado de espacios actuales del edificio principal; se señalan con una cruz $\left(^{+}\right)$aquellas conexiones que presentan dificultades en el tránsito tales como su tamaño o la necesidad de dispositivos móviles, con un asterisco (*) las que no parecen corresponder al proyecto original de la última gran fase constructiva, y entre paréntesis, las que se sumarán más adelante para una corrección hipotética del análisis. 
Id. Caracterización

Conexiones Planos

\begin{tabular}{|llll|}
\hline 25 & Cámara de tiro en el nivel 2 del borje suroeste & 3 \\
\hline 26 & Cámara de tiro en el nivel 2 del borje sureste & 3,27 \\
\hline 27 & Balcón amatacanado dispuesto en el nivel 2 entre los borjes sureste y sur, directamente sobre el acceso a la iglesia & 26,28 \\
\hline 28 & $\begin{array}{l}\text { Escalera helicoidal en el interior del borje sur, entre los niveles } 2 \text { y 3; además de comunicar los dos balcones amatacanados } \\
\text {-el superior de los cuales actualmente amortiza la escalera 29-, cuenta con un vano cegado hacia el norte entre ambas } \\
\text { alturas, posiblemente para dar acceso a un adarve intermedio hipotéticamente recogido en el espacio } 51 \text { (vid. fig. 13) }\end{array}$ & 3,4
\end{tabular}

29 Escalera que da acceso al espacio de la españada, montada a caballo de un segundo balcón amatacanado dispuesto en el 28,30 nivel 4 entre los borjes sureste y sur y la terraza del primero -amortizando ambos espacios, que se recogen a nivel hipotético respectivamente como 52 y 53 (vid. fig. 13)-

\begin{tabular}{|ll}
\hline 30 & Espadaña \\
\hline 31 & $\begin{array}{l}\text { Escalera de husillo cuya caja se adosa por el exterior al transepto de la nave norte de la iglesia, quedando posteriormente } \\
\text { integrada en la obra de la torre del homenaje; presumiblemente comunicó en algún momento los niveles } 1 \text { y } 3 \text {, pero ambos } \\
\text { extremos están condenados en la actualidad y solo puede accederse a ella en el nivel 2, a través de la escalera rampante }\end{array}$
\end{tabular}

32 Escalera helicoidal en el interior del borje norte, entre los niveles 1-2 y 2, que comuna el patio sobre la cubierta de la iglesia $0^{(57)+}, 33^{+}, 34$ con la liza mediante un dispositivo móvil que salva la altura hasta el nivel 1

\begin{tabular}{|llll|}
\hline 33 & Cámara de tiro en el nivel 1 del borje norte, accesible verticalmente mediante dispositivo móvil & & $32^{+}$ \\
\hline 34 & Patio norte; espacio sin techar sobre la cubierta de la nave norte de la iglesia & $32,35,36,(51)$ & $3,4,5,6$ \\
\hline 35 & Cámara de tiro en el nivel 2 del borje noroeste & 34 \\
\hline 36 & Cámara de tiro en el nivel 2 del borje oeste & 34 \\
\hline 37 & $\begin{array}{l}\text { Especie de pasillo de acceso a la iglesia en el nivel 1, con bancos adosados; definen su volumen los cuerpos inferiores de } \\
\text { los borjes sur y sureste, un rastrillo entre ambos, y la portada románica }, 38\end{array}$ & \begin{tabular}{l} 
1 \\
\hline
\end{tabular}
\end{tabular}

38 Espacio de la iglesia, computado unitariamente aunque probablemente pudiera compartimentarse no solo atendiendo a los $5^{\star}, 37,39,46$ criterios de convexidad sino también a la presencia de huellas que sugieren la presencia de algún tipo de barreras -hoy desaparecidas- especialmente en cabeceras y pies

$39 \quad$ Estancia en extremo noreste del nivel 1, actualmente empleada como sacristía; definen su volumen los muros de la torre del 38 homenaje y el límite exterior del antiguo ábside septentrional, parcialmente rebajado para darle acceso desde el presbiterio mayor

40 Escalera de ladrillo tabiquero hueco montada sobre la cubierta de la nave central, en el nivel 3; dado que arranca desde la $8^{+}, 41$ cornisa, se le ha de acceder mediante dispositivo móvil desde el patio sur, en el nivel 2, mientras hacia el norte se desarrolla una huella de iguales proporciones a la que sin embargo dan la espalda los escalones actuales

41 Adarve sobre el "enforrado" de la iglesia; la adición del cuerpo que sostiene la espadaña hace inaccesible el tramo terminal $40^{*}, 42,43,44,45,5,6$ sureste, contra la torre del homenaje

42 Terraza del borje suroeste 4

$43 \quad$ Terraza del borje oeste 41

$44 \quad$ Terraza del borje noroeste 41

$45 \quad$ Terraza del borje norte 41

46 Restos de una sección recta de escalera, presumiblemente con puertas en ambos extremos, dispuesta en el hueco de la 47,38 antigua portada románica occidental -visible de hecho gracias a una calicata que ha desfigurado completamente su primer tramo-

47 Cámara de tiro en el nivel 1 del borje oeste; mientras que al norte se abre una tronera, al sur queda la huella de un vano $0(57)^{+}, 46$ condenado que hubo de dar acceso a la liza mediante un dispositivo móvil que salvara la diferencia de altura

48 Estancia bajo la bóveda del crucero de la iglesia ganada mediante la interposición de la de terceletes a una menor altura, $6^{{ }^{*+}}$ que presenta buhederas y otros puestos de tiro cegados; las condiciones del acceso actual -mediante dispositivo móvil, a través de un agujero en el salón del nivel 2- no parecen ser las proyectadas originalmente, sin embargo, no hay rastro de ningún otro vano más allá de unos sillares aparentemente repuestos en la esquina sureste que tampoco pudieron permitir más que una hipotética gatera cuyo desarrollo lineal dificultaría en buena medida la propia torre del homenaje

Figura 4 (continuación). Listado de espacios actuales del edificio principal; se señalan con una cruz $\left(^{+}\right)$aquellas conexiones que presentan dificultades en el tránsito tales como su tamaño o la necesidad de dispositivos móviles, con un asterisco (*) las que no parecen corresponder al proyecto original de la última gran fase constructiva, y entre paréntesis, las que se sumarán más adelante para una corrección hipotética del análisis.

decirlo- la convexidad espacial, y por ende las intersecciones potenciales, sino partiendo de una mucho más sencilla regla de decisión aleatoria que prioriza la continuidad del movimiento revisando su dirección en un ángulo de $170^{\circ}$ cada tres pasos.
Aplicado a la planta que nos ocupa, este análisis no viene sino a ahondar en lo antedicho, presentando los cubos y otros espacios distales -entre los que se incluyen los confines de la iglesia- como zonas poco o nada visitadas y, por lo demás, unas posibilidades de circulación 


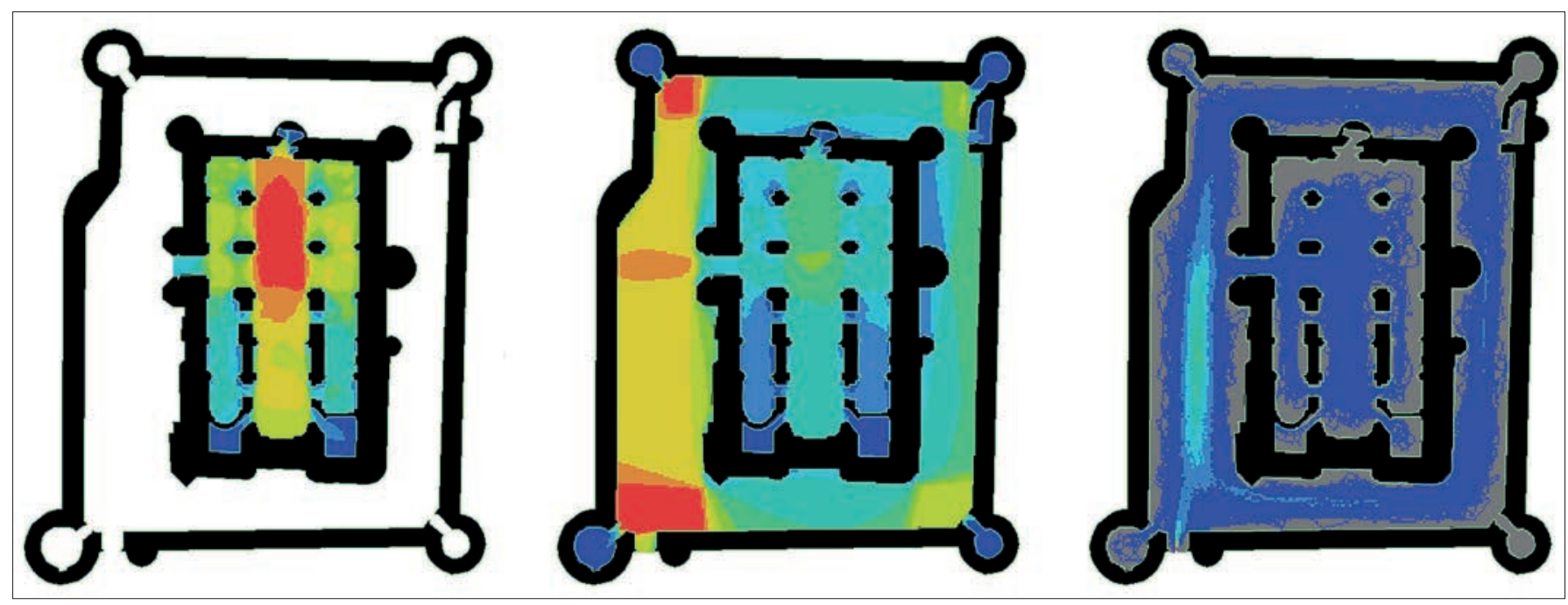

Figura 5. Grafo de visibilidad (VGA) circunscrito al interior de la iglesia (izquierda) y del total del nivel 1 en su situación actual (centro), y análisis agente del último caso (derecha) según los parámetros estándar de DepthMap X para una duración de 5000 timesteps con 50 agentes lanzados desde la puerta sureste.

relativamente homogéneas con clarísima prominencia de la fachada meridional. Y es que a fin de cuentas, puesto todo junto, queda claro que la problemática del nivel 1 del edificio está determinada por el carácter eminentemente "público" de la mayor parte de su superficie, repartida entre el templo y la liza, siendo que por norma general "los espacios más privados [...] están altamente agrupados mientras que los sociales [...] ofrecen campos de vista multidireccionales $\mathrm{y}$, por tanto, coeficientes de agrupamiento bajos, alcanzando el rango de aquellos sin llegar a injerírseles" (Turner et al. 2001: 111).

\section{LA TRIPLE TORRE DEL HOMENAJE Y EL "EJE DE HONOR"}

Volviendo al análisis de accesibilidad, basta un vistazo al grafo justificado (Fig. 6) para percatarse del alto grado de segregación del edificio, con una disposición lineal de muchos de sus espacios y desarrollos dendríticos característicos del énfasis en el control de la circulación. De todos modos, el que aparezca separado en tres partes incomunicadas no deja de ser anómalo, por más que, atendiendo al uso distintivo, pudiera llegar a justificarse en el caso de la iglesia -cuyo interior, cabe presuponer, podría batirse desde los espacios 7, 24 y 48, además de ser defendido su acceso por el matacán del espacio 27 . Sobre otorgarle un valor de control moderadamente elevado (Fig. 7), esto redunda en una integración del exterior superior a la media, algo que por lo pronto contrasta con lo registrado en la mayoría de espacios de distribución

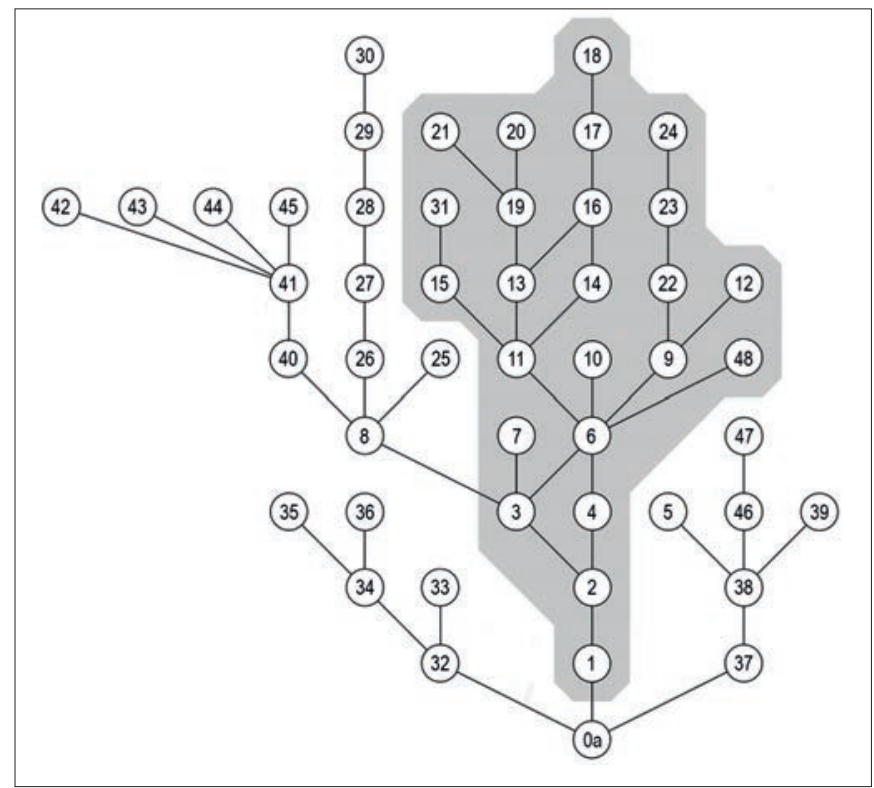

Figura 6. Grafo justificado de la situación actual del edificio principal, destacando en sombreado los espacios correspondientes a la torre del homenaje.

dada la posición que ocupan hacia el final de los subsistemas que controlan. Solamente dos de ellos rompen esta tendencia: el patio sur, por el cual se accede tanto al adarve como, lo que quizá es más importante para comprender su valor contemporáneo, al circuito que conduce a la espadaña; y el espacio 6 , correspondiente a la estancia que ocupa el nivel 2 de la torre central.

Resulta igualmente interesante que solo dentro de la torre del homenaje se localicen otros espacios con valores equiparables a los del exterior; así como que, 


\begin{tabular}{|c|c|c|c|}
\hline \multirow{2}{*}{ Tipo } & \multirow{2}{*}{ Id. } & \multicolumn{2}{|c|}{ Valores actuales } \\
\hline & & RRA & $\mathrm{CV}$ \\
\hline \multirow{15}{*}{ 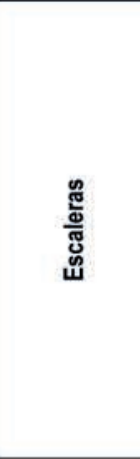 } & 1 & 1.111 & 0.66 \\
\hline & 2 & 0.963 & 1.25 \\
\hline & 9 & 1.111 & 1.66 \\
\hline & 11 & 1.037 & 1.50 \\
\hline & 14 & 1.333 & 0.58 \\
\hline & 15 & 1.333 & 1.25 \\
\hline & 19 & 1.556 & 2.33 \\
\hline & 28 & 1.778 & 1.00 \\
\hline & 29 & 2.074 & 1.50 \\
\hline & 31 & 1.630 & 0.50 \\
\hline & 32 & 1.556 & 1.66 \\
\hline & 40 & 1.185 & 0.45 \\
\hline & 46 & 2.074 & 1.25 \\
\hline & Media & 1.399 & \\
\hline & Desv. Est. & 0.374 & \\
\hline \multirow{5}{*}{ 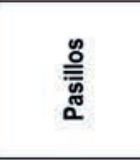 } & 4 & 1.037 & 0.50 \\
\hline & 17 & 1.852 & 1.33 \\
\hline & 37 & 1.181 & 0.58 \\
\hline & Media & 1.417 & \\
\hline & Desv. Est. & 0.408 & \\
\hline \multirow{4}{*}{$\frac{0}{\pi / 0}$} & 8 Patio sur & 0.963 & 2.25 \\
\hline & 34 Patio norte & 1.778 & 2.33 \\
\hline & Media & 1.308 & \\
\hline & Desv. Est. & 0.576 & \\
\hline \multirow{15}{*}{ 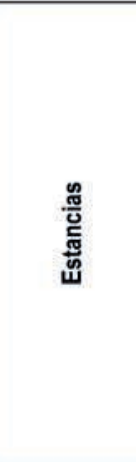 } & 3 & 0.815 & 1.75 \\
\hline & 5 & 2.074 & 0.25 \\
\hline & 6 Salón & 0.889 & 3.33 \\
\hline & 7 & 1.111 & 0.25 \\
\hline & 10 & 1.185 & 0.16 \\
\hline & 12 & 1.481 & 0.33 \\
\hline & 13 & 1.259 & 0.91 \\
\hline & 20 & 1.852 & 0.33 \\
\hline & 22 & 1.407 & 0.83 \\
\hline & 23 & 1.704 & 1.50 \\
\hline & 24 & 2.000 & 0.50 \\
\hline & 39 Sacristia & 2.074 & 0.25 \\
\hline & 48 & 1.185 & 0.16 \\
\hline & Media & 1.402 & \\
\hline & Desv. Est. & 0.439 & \\
\hline \multirow{10}{*}{ 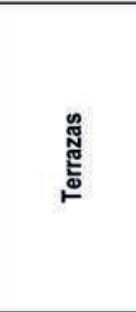 } & 16 Torre (norte) & 1.556 & 1.33 \\
\hline & 18 Torre (sur) & 2.148 & 0.50 \\
\hline & 21 Torre (central) & 1.852 & 0.33 \\
\hline & 27 Balcón amatacanado & 1.481 & 1.00 \\
\hline & 42 & 1.778 & 0.20 \\
\hline & 43 & 1.778 & 0.20 \\
\hline & 44 & 1.778 & 0.20 \\
\hline & 45 & 1.778 & 0.20 \\
\hline & Media & 1.759 & \\
\hline & Desv. Est. & 0.200 & \\
\hline \multirow{7}{*}{ 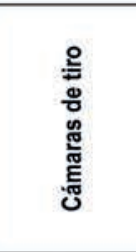 } & 25 & 1.259 & 0.25 \\
\hline & 26 & 1.259 & 0.75 \\
\hline & 33 & 1.852 & 0.33 \\
\hline & 35 & 2.074 & 0.33 \\
\hline & 36 & 2.074 & 0.33 \\
\hline & 47 & 2.370 & 0.50 \\
\hline & $\begin{array}{l}\text { Media } \\
\text { Desv. Est. }\end{array}$ & $\begin{array}{l}1.762 \\
0.461\end{array}$ & \\
\hline \multirow{4}{*}{ Singulares } & 30 Espadaña & 2.370 & 0.50 \\
\hline & 38 Iglesia & 1.778 & 3.00 \\
\hline & 41 Adarve del "enforrado" & 1.481 & 4.50 \\
\hline & 0. Exterior & 1.259 & 1.33 \\
\hline \multirow{5}{*}{$\begin{array}{l}\text { TOTAL } \\
\text { EDIFICIO }\end{array}$} & Minimo & 0.815 & \\
\hline & Media (sin exterior) & 1.519 & \\
\hline & Media (con exterior) & 1.514 & \\
\hline & Máximo & 2.370 & \\
\hline & Desv. Est. (sin exterior) & 0.408 & \\
\hline
\end{tabular}

Figura 7. Tabla de valores sintácticos actuales del edificio principal; los datos primarios (RA y CV) se obtuvieron mediante el software Agraph 3.0 para el dibujo y cálculo de grafos de nodos y axiales en sintaxis espacial desarrollado por Bendik Manum, Espen Rusted y Paul Benze [https://www.ntnu.no/ab/spacesyntax consultado el 01/04/2020]. a excepción de un caso, se trate siempre de escaleras. Y más todavía el que esa excepción sea precisamente la del espacio 3, que comunica los espacios 8 y 6 por el nivel 2 de la torre sur. Ello sitúa esta estancia en el centro de la zona mejor integrada de todo el sistema, una vez se ha ingresado al edificio por el patín que hoy día salva la altura entre la torre sur y la liza, y se ha recorrido un primer tramo acodado de escaleras. También se encuentran en el interior de la torre del homenaje los dos únicos anillos del sistema: entre los espacios 2 y 6 , cruzando alternativamente 3 o 4; y entre los espacios 11 y 16, haciéndolo por 13 o 14 .

Este último permite explicar la lógica circulatoria de la parte alta del edificio, que todo parece indicar, no bascula tanto sobre esa mínima alternativa como sobre el establecimiento de conexiones directas entre las tres terrazas de la torre y la estancia central del nivel 3, patentizando que los valores sintácticos -en principio poco significativos aquí- no se entienden correctamente separados del resto de circunstancias conocidas, empezando por las morfológicas. En efecto, ese espacio 13 es el único techado dentro del anillo al que puede pensársele una función planificada diferente al mero tránsito; y que pueda evitárselo para alcanzar la terraza norte desde abajo, y desde ahí la sur a través del espacio 17 -un corredor flanqueado por rastrillos-, no resulta tan determinante como que situándose a media altura en ese mismo recorrido, sea el único que da acceso a la terraza central. Nótese, además, que al disponerlos de tal manera se está generando un efecto añadido por el cual el espacio más alto no es el más profundo, lo que sí será significativo a la hora de extraer conclusiones.

Por su parte, la estancia 3 juega un papel similar en cuanto a la comunicación en un nivel más bajo, y mucho más integrado. Sin embargo, en su caso, incluso dejando de lado la posición de control global que desempeña la estancia 6 como paso obligado hacia cualquier otra parte de la torre, y pensándola localmente, la carga significativa evidenciada en sus dimensiones o en la presencia allí de una de las tres únicas chimeneas -junto con las de los espacios 10 y 12- dirige hacia sí la circulación en el anillo de una manera que desde luego no lo hace la terraza 16. Esto se refleja también en los espacios que le están por debajo, de manera que donde el sistema de escaleras y rellano del espacio 11 aparece como un punto de distribución más o menos indiferenciado, el último codo del espacio 2 presenta un parapeto aspillerado, vuelto sobre la propia escalera y un ensanchamiento en forma de cámara de tiro con bancos adosados, aproximadamente a 
la altura en que se abría asimismo el vano hacia el espacio 3 -hoy ampliado y enlucido-, que se perfila como un punto de detención y filtrado en el proceso de recepción formal de agentes externos exactamente en los mismos términos en que Mol recogía las conclusiones de Philip Dixon para casos británicos: "existe un espacio en todos los castillos con la función de área de espera [holding area] adyacente a una cámara señorial o salón privado; el propósito de esta compleja aproximación era social y no militar, y se refería al trato con amigos y rivales, no con enemigos" (Mol 2012: 148).

Así las cosas, la estancia 3 habría podido organizar la circulación cotidiana independiente o paralelamente a la representación social, permitiendo que, según las circunstancias, determinados agentes internos evitaran verse expuestos en sus movimientos entre la torre del homenaje, el patio sur y el exterior, mientras se derivaba el tránsito de los externos por el pequeño pasillo 4 . No por nada, la clave de la distinción que Mol establece entre los castillos de órdenes religiosas y los aristocráticos radica en la voluntad en estos de "enmarcar el espacio en una conducta jerárquica" que combina la privacidad y la publicidad del poder señorial mediante un dominio excluyente del entorno, frente a las configuraciones menos profundas y lineales de aquellos, expresión material de la vigilancia de la convivencia monástica. Uno de los dispositivos más característicos de esa voluntad sería el desarrollo, especialmente en la Baja Edad Media, de rutas ceremoniales hasta las cámaras principales del edificio conocidas como "eje de honor" (Fairclough 1992; Richardson 2003), que es precisamente a lo que responden el pasillo 4 y el área de espera previa en Turégano. En este sentido puede considerarse aun la direccionalidad de las rutas, siendo que si el exterior nominal o cognitivo se entiende pautado por las molduras de las jambas de las puertas, ese pasillo juega a invertir su percepción a ambos lados de modo tal que quien lo transita se mantiene siempre "fuera", reforzando la idea del salón como un primer punto de llegada. Un espacio "público" de representación en el interior de un sistema privado.

Por detrás de él quedan dos estancias distintivas, como decía, que podrían adscribirse a ese eje con ciertas diferencias. De un lado, el acceso al espacio 10, en el nivel 3 de la torre sur, se ubica entre el vano por el cual se baja al espacio 3 y el que sube al espacio 11, con quien comparte algunos escalones. En el lado opuesto del salón, otro sistema de escaleras conduce bien a una zona muy afectada por calicatas contemporáneas, sobre el ábside de la nave norte de la iglesia y a través de la cual se accede a las cámaras interpuestas bajo su bóveda, bien a la estancia 12. La mayor profundidad que en consecuencia ostenta esta respecto a su contraparte meridional podría mover a identificarla con los aposentos principales, y desde luego cabe esta posibilidad. Pero más allá de una orientación menos benigna que la de la estancia 10, la posición de la estancia 12 maximiza el control de los movimientos de sus ocupantes, alejándoles de las salidas y circuitos defensivos; y quizá no solo de sus movimientos, si acaso ha de valorarse el que el conducto de humos de su chimenea evacúe por la terraza norte, mientras que la de la estancia 10 lo hace por la mucho menos accesible terraza central.

\section{EL PROBLEMA DE LAS ESCALERAS, O LO QUE QUEDA DE LAS FORTIFICACIONES PREVIAS}

Afinar este análisis y llevarlo más allá de los rasgos generales de la torre del homenaje -que pueden afirmarse ya más o menos invariables desde su diseño- requiere aclarar la contemporaneidad de determinadas comunicaciones, para sumarlas o restarlas al modelo, así como la probabilidad de espacios hoy desaparecidos.

Es evidente que las obras de la espadaña no responden al proyecto original entre otras cosas porque interrumpen el adarve y prácticamente inutilizan el segundo balcón amatacanado y la terraza del borje suroeste. El asunto es más complicado con elementos como la escalera rampante a la cual se accede -con dificultades- a través de una abertura practicada en el suelo del rellano de distribución del espacio 11, en el interior del antiguo campanario, descendiendo hasta la mitad de una escalera de caracol cegada en ambos extremos al momento de realizarse este estudio. Este sistema, representado en los espacios 15-31, permitió la comunicación entre el interior de la iglesia y el castillo, como queda atestiguado en las huellas de un tapiado en el muro septentrional del transepto de la nave norte y en la memoria de algunos habitantes de Turégano; pero por sí solo, eso no implica que el acceso deba considerarse funcional en un modelo hipotético. Es en este punto donde se hace imprescindible la retroalimentación que ofrece un análisis estratigráfico siquiera preliminar, si bien el carácter harto fragmentario e inconexo de las evidencias dificulta una interpretación global definitiva, que en ciertos aspectos no puede sino quedar supeditada a futuras intervenciones. 
Que hubo un recrecido por lo pronto de las cabeceras de la iglesia de San Miguel es un hecho contrastado por las calicatas masivas sobre sus naves laterales, en los espacios 3 y 22 , donde quedan al descubierto sendos muros proyectando verticalmente la curvatura de sus ábsides al menos hasta la altura del techo del nivel 2, así como las huellas de un tejado por debajo de los niveles de suelo de la torre del homenaje. Precisamente la conservación funcional de los tejados, inferida de la presencia de desagües en la base de dichos muros, hace pensar que estos volúmenes carecieron tanto de cubiertas como de un firme de obra, pudiéndose practicar la circulación al nivel de las saeteras por medio de tablados. Eso es todo lo que se puede concluir de la situación actual de la estancia 3 (Fig. 8), donde puede apreciarse cómo el muro se rebajó posteriormente a cota del suelo conservado para el nuevo espacio interior de la torre sur, que así se ensanchaba, pero queda cubierto lo demás por revocos.

La situación es diferente en la torre norte (Fig. 9). Allí las obras bajomedievales cortaron en principio el recrecido para cimbrar la bóveda que cubre el actual espacio 22, y a juzgar por las huellas en esa misma bóveda, para dar acceso al volumen que la torre del homenaje ganaba por el este. Parece sin embargo debérsele a las rebuscas contemporáneas la eliminación del resto del muro, lo que, sumado a la ausencia de revocos, permite distinguirle hasta tres acciones constructivas:

1. Un cuerpo de calicanto muy similar al de la obra de la iglesia, que perimetra el ábside sin otra solución de continuidad aparente que la rotura contemporánea.

2. Sobre él, en la mitad oeste, un segundo cuerpo ligeramente más estrecho, caracterizado por contener un elevadísimo número de tejas rotas.

3. Y, por último, un tercer cuerpo en la mitad este, compuesto por verdugadas de ladrillo macizo alternadas con paquetes de mampuestos.

Más allá de las estrictas relaciones de anterioridadposterioridad no es mucho lo que puede extraerse hasta aquí del proceso general, como tampoco del tiempo transcurrido entre unas y otras acciones. De hecho, en los restos meridionales del recrecido ni siquiera se detecta con claridad un interfaz equivalente al que separa los cuerpos 1 y 2 , aunque en efecto, también se cumpla el criterio de hallar ímbrices embebidos en las partes media y alta, pero no en la baja -y nunca ladrillos-. De confirmarse este punto resultaría un escenario compuesto por más de un proyecto de fortificación previo al conservado, donde

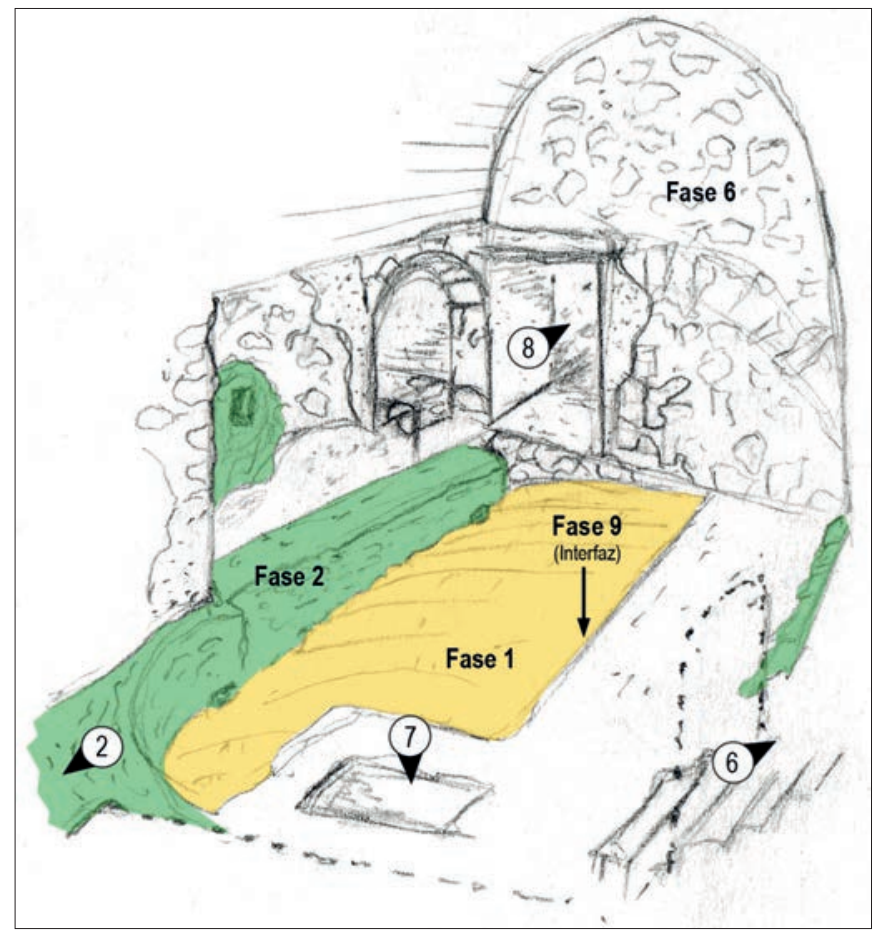

Figura 8. Croquis del espacio 3 en perspectiva ideal desde el noreste.

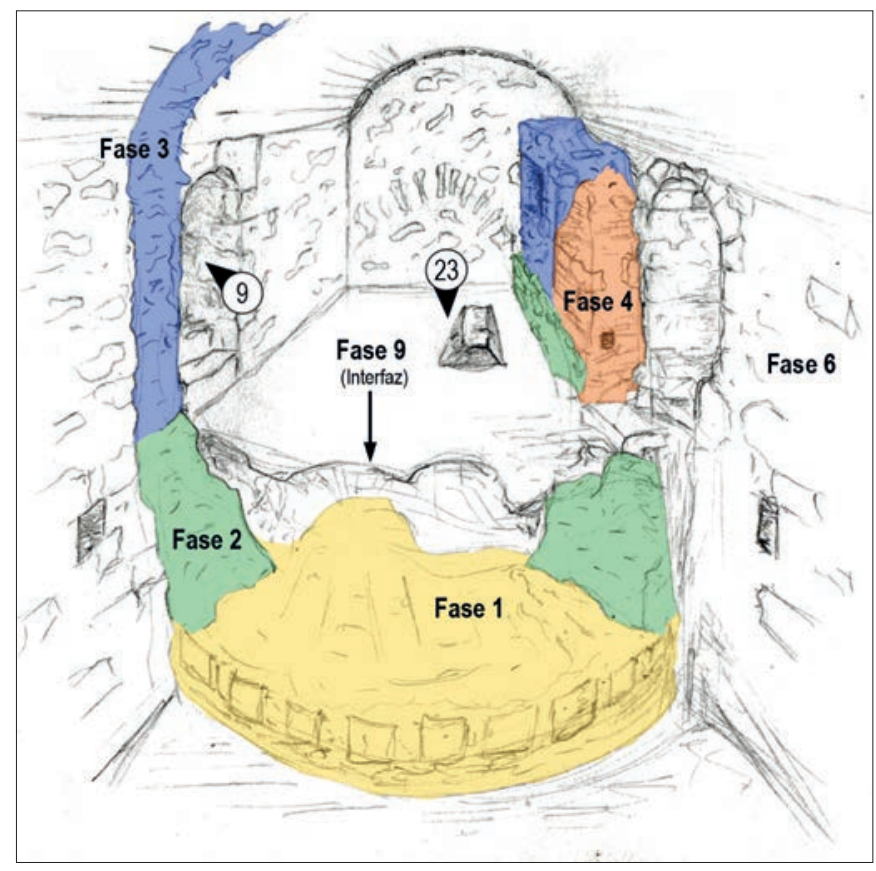

Figura 9. Croquis del espacio 22 en perspectiva ideal desde el este; nótese que, según la restitución hipotética de su compartimentación, los espacios 49-50 quedarían en primer plano.

al menos en esta parte, al levantamiento de un primer parapeto seguiría un verdadero "torreado" que amortiza el tejado original y habilita nuevos espacios techados, entre los cuales encaja pensar las cámaras bajo las bóvedas no solo por motivos técnicos, sino también defensivos. Pero 
las evidencias todavía informan de una remodelación de cierta envergadura sobre un vano abierto en dirección norte, por más que se desconozca la naturaleza exacta tanto del vano como de su reforma, y aquí conviene volver la vista hacia el sistema de escaleras $15-31$, justo al otro lado del cierre occidental del espacio 22.

Como decía, la rampante no alcanza la cota de suelo del espacio 11 sino que ingresa al campanario directamente por lo que fue el alféizar. A esto se suma, para considerarle una construcción anterior al último proyecto, la alternancia en su recorrido de pequeños vanos a ambos lados, hoy cegados (Fig. 10). Sin embargo, ninguno de ellos se corresponde en tamaño y posición con la puerta condenada que antes del llagueado de la torre del homenaje, durante una restauración en 2003, todavía podía observarse desde el patio 34 a cierta altura; concretamente, a la altura de un almenado conservado por bajo del del castillo actual (Fig. 11). Esta circunstancia devuelve a su vez la atención hacia la escalera de caracol y a dónde conducía antes de tapiarse. Pero sucede que, además de resolverse apuntando al este, en dirección contraria, la caja turriforme que la aloja se adosa al cuerpo de la iglesia, lo que consiguientemente la sitúa por fuera del edificio. Ambas circunstancias desembocan en una de las preguntas quizá más importantes de las muchas que no se pueden responder: ¿conducía entonces al espacio sobre el ábside norte, accediendo por el vano que modificará la

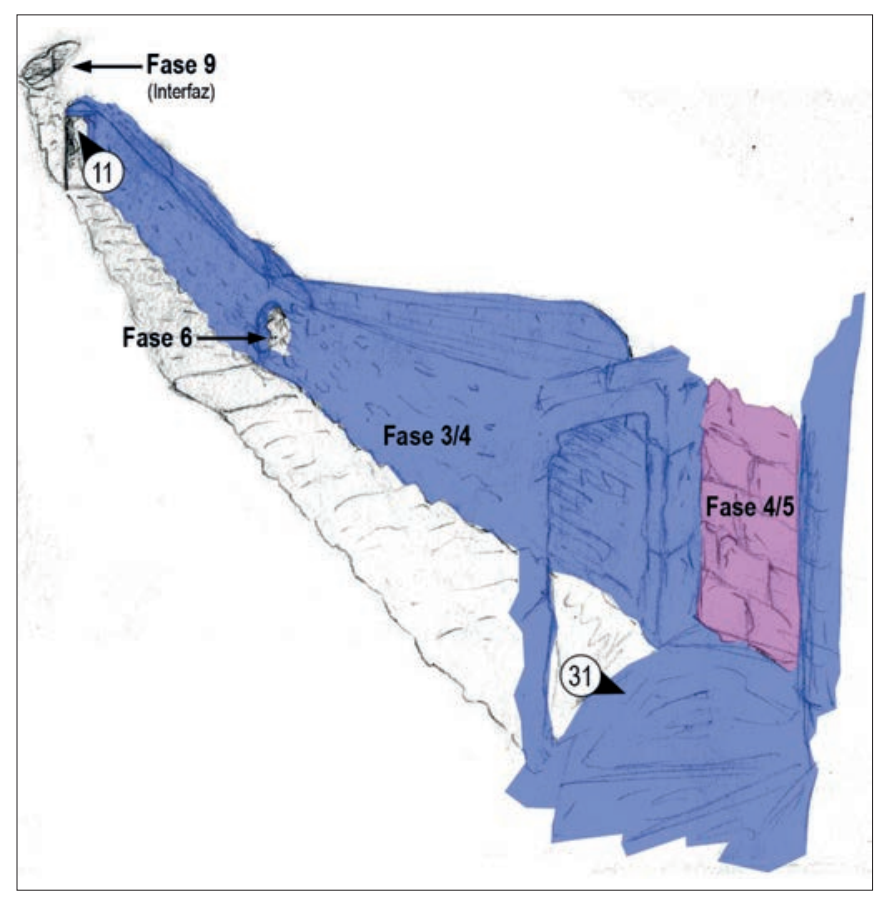

Figura 10. Croquis de los espacios 15 y, parcialmente, 31 en perspectiva ideal desde el noreste del nivel 2. obra de ladrillos tal vez mediante una pasarela o cadalso, y se accedía desde allí al adarve del antiguo almenado, por el vano que invisibilizó la restauración?

Sea como fuere, observar el edificio desde los patios permite concatenar todavía un par de ideas más. En primer lugar, está un desconchado en los revocos del muro que separa la estancia 3 del patio 8 , donde un mechinal y algunos ladrillos anuncian un paramento técnicamente distinto al del resto de la torre del homenaje, sugiriendo que en algún momento una compartimentación de lo ganado sobre ambas cabeceras pudo prefigurar la distribución del espacio que conservamos hoy. Más determinante resulta advertir cómo, junto a la reducción de la ventana occidental del campanario a lo que parece una ladronera, se registra una ampliación en mampostería del volumen de su torre apoyada en el hombro sur, en la base de la cual vuelve a encontrarse un desagüe. Este cuerpo de obra, si acaso morfológicamente comparable con la caja de la escalera 31, redunda en la idea de que el proceso de fortificación no se reduce a un único proyecto previo; o a un proyecto invariable. No se comprende de otro modo el replanteo del vano habilitado entonces contra el machón meridional del campanario, recortado más tarde a cota de aquella ladronera y, al contrario que esta, totalmente cegado por un relleno que probablemente se explica en el contexto de la cimentación de la actual torre del homenaje. El mismo relleno -por cierto- que condenó la escalera rampante; y que hubo de ser perforado para darle de nuevo acceso, en un pasado por determinar.

\section{UN CASTILLO HIPOTÉTICO}

Desgraciadamente, lo antedicho no implica que pueda componerse una imagen completa de estos procesos de fortificación, donde las diferentes acciones constructivas detectadas aquí y allá se agrupen en fases definidas al margen de toda duda. En su lugar, no hay más remedio que hipotetizar esas fases asumiendo ciertos apriorismos dentro del marco de las relaciones estratigráficas constatadas positivamente, como la mayor o menor lógica funcional de teóricas soluciones arquitectónicas, o la homogeneidad de las fábricas. Y en ese sentido el salón reaparece como un espacio definitorio, por razones muy distintas a las anteriores.

Además de las huellas del recrecido de presbiterio y ábside mayor, puede apreciarse allí parte de la obra en sillería de la ventana oriental del campanario románico. La cuestión es que, antes de cegarla definitivamente 


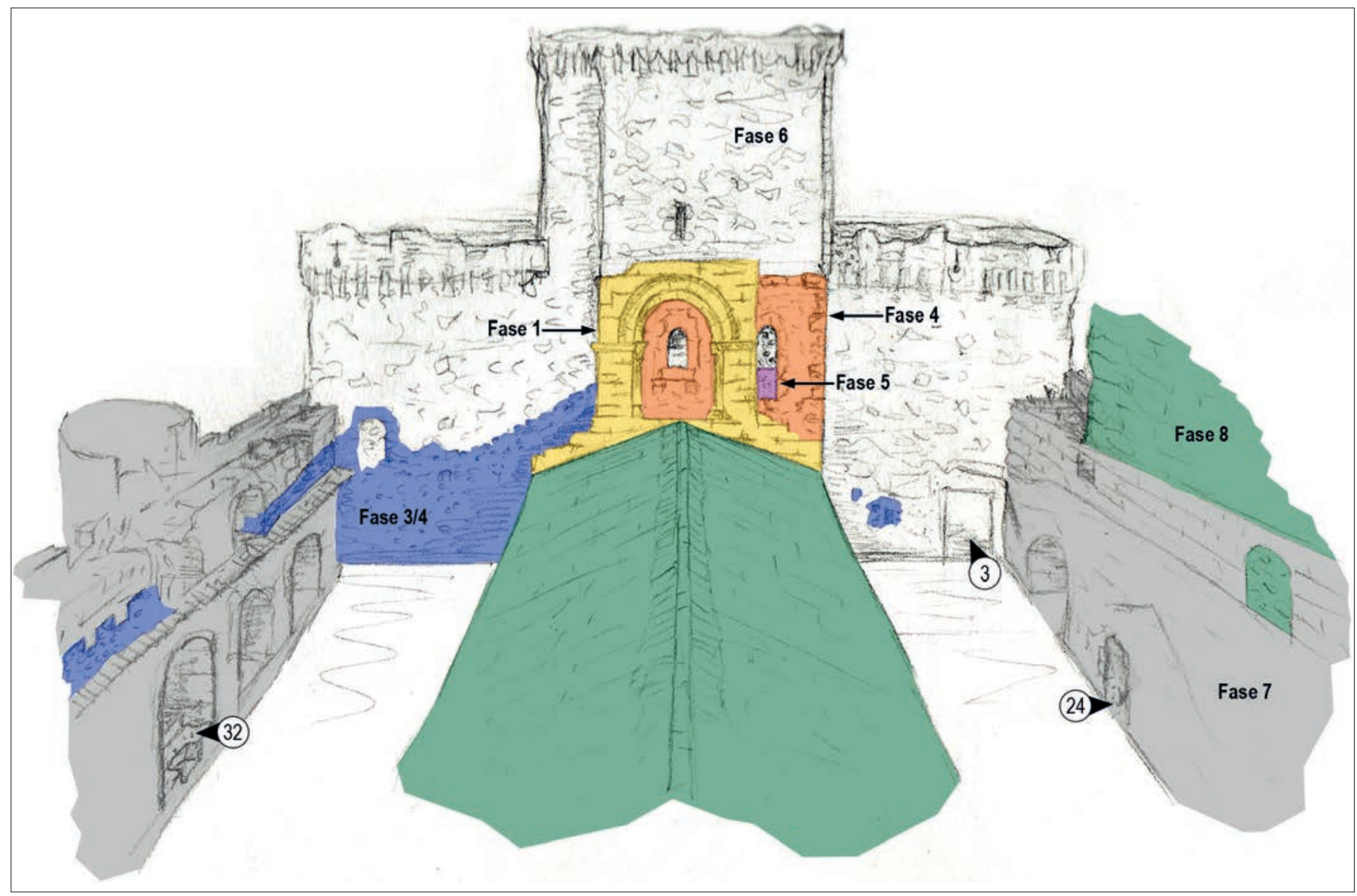

Figura 11. Croquis de los espacios 34 (izquierda) y 8 (derecha) en perspectiva ideal desde el oeste.

para integrarla en el muro de mampostería del proyecto del castillo actual, se redujo su vano mediante un arco sobre machones de ladrillo como los empleados en la reforma de la estancia 22 (Fig. 12), lo que proporciona un indicio para sospechar que la amortización total del campanario no se produjo sino en un momento avanzado. Podría plantearse entonces que una vez levantadas como mínimo las cabeceras de la iglesia de San Miguel en la fase 1, pero no necesariamente finalizadas unas obras que de hecho apuntan a un profundo replanteo de sus cubiertas a mitad de ejecución, se proyecta una primera fortificación con la construcción de los parapetos no techados de la fase 2. Este escenario puede rastrearse en ambas naves laterales, pero ciertamente, tampoco es óbice para dar por sentado un desarrollo simétrico del edificio; máxime cuando las propias escaleras 31-15 son muestra de lo contrario. De hecho, la adscripción de esta pieza a una fase $u$ otra resulta harto complicada, pues si bien parece lógico presuponer que fuera cual fuese la superficie de cubiertas afectada por esa primera fortificación, su acceso debió realizarse desde el interior

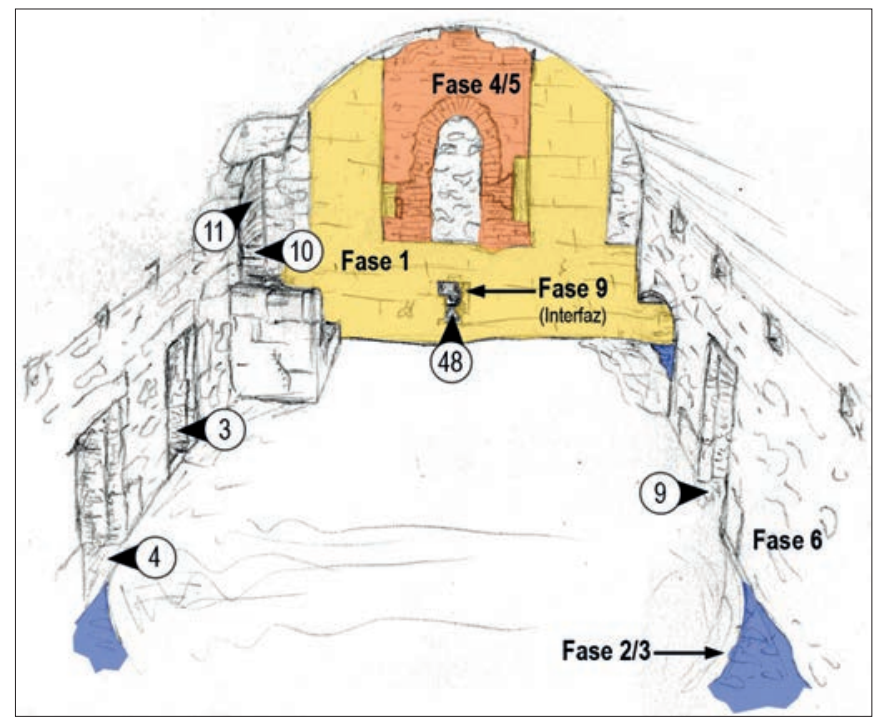

Figura 12. Croquis del espacio 6 en perspectiva ideal desde el este.

del edificio para aprovechar el espesor de sus muros, del otro lado guarda cierto parecido técnico con la ampliación del campanario, que pudiera relacionarse a su vez con las últimas reformas del torreado del ábside norte. 
No en vano, las fases 3 y 4 representan el punto más confuso de la secuencia. Todo parece indicar que al menos sobre ese ábside se amortizó el tejado y se utilizaron sus ímbrices en un segundo recrecido cuya altura coincide con un almenado que perimetraría el resto del edificio. Paralelamente, el vano que dio servicio a su adarve informa de un nivel de suelo ostensiblemente por encima de las cubiertas de la nave, y de la escalera rampante, lo que termina de justificar el acondicionamiento de unos espacios techados que ya insinuaban las cámaras interpuestas bajo las bóvedas de sendas cabeceras laterales, cuyas bocas de tiro - de nuevo, al menos al norte- protegen precisamente el punto por el que se accedía desde la iglesia a la escalera de caracol.

Estas acciones podrían englobarse a grandes rasgos en una misma fase sin necesidad de forzar la estratigrafía que se observa a simple vista, pero al llegar al campanario y la nave central la cosa se complica. Aunque el resultado final aquí es coherente con lo que cabría esperar de lo planteado en la fase 3 -es decir: ganar una altura adicional para la defensa y facilitar la circulación interna del edificio obtenido entonces-, la separación cautelar en diferentes fases responde al apriorismo de considerar que todas las ventanas del campanario se redujeron a la vez. Podría imaginarse que lo registrado en ese momento con los ladrillos del espacio 22 es el cegamiento de un primer acceso por el exterior de la fachada septentrional una vez habilitada una mejor comunicación interior; imaginar, incluso, que la fase 3 se circunscribiese solo a las obras previas en aquel sector, y todo lo demás se ejecutara en la siguiente, pues al fin y al cabo también se documentan algunos ladrillos en el cierre occidental del espacio sobre la cabecera sur; pero lo cierto es que no hay elementos suficientes como para asegurar nada de esto.

Ni siquiera los hay para acabar de relacionar lo que sucede en el campanario con la fortificación de la nave central, donde la cota de suelo fue forzosamente la misma que la actual pero no se puede rastrear bien la altura del recrecido ni dentro de la chimenea del espacio 6 ni en el nivel 4, a pesar de constatarse ciertas irregularidades en la estancia 13 cuya continuidad y naturaleza impide verificar el solado del pasillo 17. Desde luego, que se mantenga un vano a ras del alféizar de la ventana del campanario se explica o bien porque algún dispositivo salvaba la diferencia de cota con el conservado, o bien porque existía otro nivel de suelo, definiendo entremedias un espacio cuyo cielo apenas habría superado los $2 \mathrm{~m}$. Y esto aun dejaría abierta la posibilidad de que, fueran cuales fuesen sus características, el paño de ladrillos únicamente estuviera dividiendo un espacio originalmente continuo, en una imprecisa y laxa fase 5 que comprendería asimismo remodelaciones como el tapiado superior de la escalera 31 o la reducción del vano que la ampliación del campanario había habilitado sobre la cubierta de la nave central.

En cualquiera de estos supuestos esa ampliación del campanario se perfila más y más como otra caja de escaleras, comunicando en este caso el nivel al que ingresa la rampante desde la iglesia con una terraza superior de alcance desconocido, y hacia abajo, tal vez con el nivel de suelo del espacio 6, y con patios y adarve, a través del dicho vano. Esta idea adquiere mayor consistencia a la luz del carácter de nudo de comunicaciones que mantiene el posterior espacio 11, a pesar de ver reducidas su conectividad relativa y control. Porque si se desprende algo de lo dicho es que la estructuración espacial de las fortificaciones previas debió ser más lineal; aunque desconociendo información tan básica como si siempre fueron accesibles por las medianeras las estancias sobre las cabeceras, o si los cegamientos de la fase 5 corresponden a la abertura de caminos alternativos o solo a una reconfiguración restrictiva de la circulación, sea definitivamente inviable componer una sintaxis hipotética que analizar. Si se desprende algo más, es que la amortización durante la fase 6 del nivel de uso del campanario supone un giro en esa configuración, que plantea desde el principio desligar su acceso del templo. Nada sugiere que se hubiera pensado conservar la ruta por las escaleras 31-15 salvo lo pertinente que pueda parecer hoy día una comunicación directa entre los aposentos del señor del castillo y la iglesia, cuyas condiciones -hay que reconocer, sin embargo- distan mucho de ser "señoriales". Así las cosas, el mismo proyecto de la triple torre del homenaje hubo de planificar en origen una forma de ascender hasta la puerta actual, y que el documento de 1471 dé cuenta de esta necesidad junto con la construcción de la falsabraga probablemente solo confirma una ejecución secuencial y no simultánea de los trabajos.

De hecho, ya avanzaba cómo la opinión mayoritaria atribuye también el "enforrado" de la iglesia a unas obras desarrolladas "con el mismo plan y sin solución de continuidad temporal" (Bermúdez y Marqués 2016: 257), independientemente de que se les hayan propuesto periodizaciones atendiendo a rasgos como la presencia de los escudos episcopales de Juan Arias del Villar (1498-1501), en la fachada monumental y dos borjes del paño oeste, y Diego Ribera (1511-1543), en el borje norte, cuyo espacio 32 contiene la escalera helicoidal que comunica a cierta 
altura la liza con el patio septentrional. Esto explicaría anomalías como las cámaras de tiro incomunicadas en la esquina noroeste del nivel 1 -de las que aún se discute si su acceso original fue destruido o si no llegó a construirse debido a la obsolescencia poliorcética del proyecto hacia su finalización- o el cuerpo cilíndrico del extremo noreste -que suele considerarse un contrafuerte, aunque personalmente, vista la correspondencia de hiladas con la parte baja del muro y que alcanza precisamente la altura del antiguo almenado, más me parece un borje inconcluso probando otro replanteo sobre la marcha-; pero por aho$\mathrm{ra}$, basta con englobar funcionalmente todo esto en una fase 7. Lo mismo sucede con la fase 8, que comprendería en adelante modificaciones y reformas de un castillo "terminado" casi con total seguridad ejecutadas en momentos muy diferentes de su devenir histórico, como pudieron ser las compartimentaciones del patio sur que atestiguan algunas improntas de tejados o, por supuesto, la adición de la espadaña.

Quizá solo deban distinguirse aquí a efectos prácticos, en una fase 9 , las calicatas que exploran y rehabilitan compulsivamente cuantos espacios relictales quedaban en el edificio. Ese parece ser el caso del volumen ganado bajo la bóveda del crucero merced a la interposición de la de terceletes, tanto tipológica como arquitectónicamente relacionada con el proyecto de fortificación bajomedieval, al que actualmente se accede escala mediante, a través de un butrón en el salón, sin que una vez dentro pueda advertirse evidencia clara de otro acceso a pesar de contar con bocas de tiro. Como parece ser, en fin, el caso de las problemáticas escaleras 31-19.

\section{EL CASTILLO ACTUAL EN TÉRMINOS IDEALES}

Si el estado actual del conocimiento no aconseja arriesgarse a incluir los anteriores en un modelo hipotético en la medida en que podrían comprometer o desvirtuar el resultado del análisis, quedan sin embargo un puñado de espacios y conexiones altamente probables al término de la última gran fase constructiva (Fig. 13).

En cuanto al edificio principal, la restitución de las compartimentaciones perfectamente atestiguadas en el espacio 22 no varía la posición global del subsistema articulado en los niveles inferiores de la torre norte, que convertido en la zona de menor integración de todo el conjunto -solamente superará sus cifras la terraza sur (Fig. 14)-, continúa perfilándose como un área tan privada como secundaria. Por su parte, el volumen ganado por la torre sur en el nivel 1 lo ocupa el espacio 5 , tradicionalmente identificado como una mazmorra. Se accede a día de hoy por una amplia y tosca rotura en la nave central de la iglesia; pero la ausencia de un acondicionamiento equiparable al del espacio 39 , en el lado opuesto, y sobre todo la existencia de una abertura perfectamente escuadrada y cegada por varias losas en el techo llevan a pensar que en tiempos únicamente comunicó con el espacio 2, que habría gozado entonces de mayor valor de control. Esto repercute obviamente también en la iglesia, que lo pierde a pesar de mantenerse por encima de la media. Y otro tanto sucede con su integración, reducida significativamente a pesar de haberse contemplado en el proyecto de fortificación bajomedieval un acceso alternativo por los pies del edificio, a través de un tabuco en el borje oeste que se comunicaba, de un lado, con la iglesia gracias a un tramo de escaleras alojado en el antiguo vano románico, posiblemente con puertas en ambos extremos, y del otro, con el exterior mediante un portillo elevado sobre la liza.

Más controvertidos resultan los espacios en torno a los patios. Parece indiscutible que existió un nivel de uso compuesto quizá por tablados apoyados en el saliente del adarve que amortiza el "enforrado", pues no se entiende de otro modo la presencia a dicha altura de cámaras de tiro con bancos corridos y troneras y, sobre todo, de un vano hoy cegado comunicando con la escalera 28, que se desarrolla dentro del borje sur, entre los niveles 2 y 4 . Cabe por supuesto la posibilidad de que ese espacio no fuera continuo, aunque lo cierto es que la disposición de tales elementos espaciada por los tres paños así lo sugiere, y parece también lo más recomendable para componer una hipótesis sintáctica. Otra cuestión son sus conexiones más allá de dicha escalera, si bien la misma lógica sintáctica pide al menos otra comunicación con un patio norte que de lo contrario habría quedado aislado -tal vez apoyándose en la cubierta central y por eso se conservan algunos canecillos sin rasurar en el extremo occidental de su cornisa-, y muy posiblemente con el adarve superior, siquiera porque nada impide tampoco que pudieran transitarse con poco esfuerzo casi por cualquier punto. Sea como fuere, ese adarve superior contó con un acceso cómodo por el balcón amatacanado del nivel 4, entre los borjes sureste y sur, donde desemboca aquella escalera 28 . Se puede constatar asimismo la conexión entre el balcón y la terraza del primero de estos borjes mediante una pequeña escalera encajonada, diferente de la voladiza que 
49 Estancia en el nivel 2 de la torre norte actualmente integrado en el espacio 22, del cual hubo de separarlo el recrecido del ábside de la iglesia a juzgar por la huella conservada en buena parte de la bóveda; sendas líneas de mechinales en los muros septentrional y meridional indican que hubo de existir un suelo de madera proyectando el nivel del habilitado sobre la cubierta de la nave norte, y separando a su vez esta estancia de la hipotética estancia 50

50 Estancia en el nivel 1-2 de la torre norte actualmente integrado en el espacio 22, y concretamente bajo la hipotética estancia 49; la ausencia de otros restos de obra hace conjeturar que pudiera accederse mediante dispositivos móviles

51 Problable adarve intermedio a base de tablados apoyados en los restos de un recrecido perimetral del perfil de la iglesia anterior a la fortificación actual; su existencia funcional se constata, no obstante, por los puestos de tiro mantenidos a ese nivel en el "enforrado", así como por el vano que lo habría conectado al espacio 28

52 Balcón amatacanado en el nivel 4 entre los borjes sureste y sur, actualmente visible pero inutilizado por la escalera $29 \quad 6$

53 Terraza del borje sureste, actualmente visible pero inutilizada por la escalera 29

54 Probable terraza del borje sur, actualmente amortizada por la españada que impide cerciorarse de unas condiciones (52) de acceso y uso originales que solo pueden suponerse equivalentes a las de la contigua terraza 53

55 Probable alcazarejo, hoy día integrado en la liza indiferenciada pero bien definido por sendas huellas de muros en los paños 0 b, (56), 60 oriental y meridional de la falsabraga, que presumiblemente se encontrarian en un punto cercano al inicio del patín actual; además del que lo conecta con el exterior por la puerta sureste, esas huellas permiten constatarle otro vano ligeramente desenfilado hacia el hipotético espacio 56

56 Probable patio frente a la iglesia, actualmente integrado en la liza indiferenciada pero bien definido al oeste por las huellas en 37, (55), (57) falsabraga y "enforrado" de un muro diafragma -con el parapeto vuelto hacia sí-, y al este, por el mismo muro que delimitaría el alcazarejo; únicamente puede confirmarse la presencia de vanos en esta última dirección, apoyado uno en la falsabraga y otro en la torre del homenaje, justo bajo las escaleras que hoy le dan acceso

57 Probable forma original de la liza, limitada al espacio de circulación entre la falsabraga y el edificio principal por sus lados $32^{+}, 47^{+},(56),(58)$, 1 oeste, norte y este; precisamente el extremo meridional de este lado es el que en principio reviste mayor interés, siendo que $59,61,62,63$ además de poderse haber prolongado transversalmente hacia el patio 56 siguiendo el muro cuya huella se aprecia en la falsabraga, puede advertirse aquí un vano de pequeñas dimensiones acompañado de algunos escalones que pudiera corresponder al acceso al adarve 64 -no documentado en ningún otro sitio- a través de uno o más espacios hipotéticos

58 Espacio o espacios hipotéticos conectando el nivel de suelo de la liza y el del adarve de la falsabraga, que es a la sazón el del probable alcazarejo y el acceso a la torre del homenaje; habida cuenta de la imposibilidad de contrastar otras evidencias, la opción más sencilla supondría que esa ascensión se realizó a través del pequeño vano atestiguado en el extremo sureste del espacio 57, quizá gracias a una escalera embutida en el muro que lo separa del alcazarejo

\begin{tabular}{|c|c|c|c|}
\hline 59 & Pasillo acodado que da acceso a la liza desde la puerta noroeste & $0^{b}, 57$ & 1 \\
\hline 60 & Cámara de tiro en el nivel 1 del cubo sureste & 55 & 1 \\
\hline 61 & Cámara de tiro en el nivel 1 del cubo noreste & 57 & 1 \\
\hline 62 & Cámara de tiro en el nivel 1 del cubo noroeste & 57 & 1 \\
\hline 63 & Cámara de tiro en el nivel 1 del cubo suroeste & 57 & 1 \\
\hline 64 & $\begin{array}{l}\text { Adarve sobre la falsabraga; la proyección total o parcial de las terrazas de los cubos orientales lo segmentan obligando } \\
\text { a salvar algunos escalones para transitar entre las rondas norte-este y sur-este, sin embargo su hipotética prolongación sobre } \\
\text { los muros que definen los espacios } 55 \text { y } 56 \text { lo habría reconectado a una misma cota -la del acceso a la torre del homenaje-, } \\
\text { permitiendo mantener su unidad sintáctica sin mayores problemas }\end{array}$ & $\begin{array}{l}(1),(58), 65,66, \\
67,68\end{array}$ & $2,3,4,5,6$ \\
\hline 65 & Terraza del cubo suroeste & 64 & $2,3,4,5,6$ \\
\hline 66 & Terraza del cubo noroeste & 64 & $2,3,4,5,6$ \\
\hline 67 & Terraza del cubo noreste & 64 & $2,3,4,5,6$ \\
\hline 68 & Terraza del cubo sureste & 64 & $2,3,4,5,6$ \\
\hline
\end{tabular}

Figura 13. Listado de espacios que, sumados a los referidos en la figura 4, completan el total hipotético del conjunto arquitectónico en su última gran fase constructiva; se señalan con una cruz $\left(^{+}\right)$aquellas conexiones que presentan dificultades en el tránsito tales como su tamaño o la necesidad de dispositivos móviles $y$, entre paréntesis, las que no pueden constatarse positivamente en las condiciones actuales.

se habilitó con la espadaña; y aunque precisamente esta última obra impide asegurarlo, cabe suponer que otro tanto sucedía con la terraza del segundo.

Por lo que respecta a la introducción de los espacios que define la falsabraga, puede comenzar notándose cómo la tendencia que presentaba el exterior en el primer análisis se invierte cuando se sitúa más allá, con valores relativamente discretos en un sistema de media ahora menos integrado computándolo que de lo contrario. Esto evoca uno de los fenómenos detectados indistintamente del genotipo por Mol (2012: 172): “todos los castillos para los que se conoce una marcada función defensiva se tornan más integrados cuando se ignora el exterior", variando su MRRA en una horquilla de -0.005 a -0.170; o más significativo, visto del revés: "los tres castillos de nuestro análisis [de un total de trece] de 


\begin{tabular}{|c|c|c|c|}
\hline \multirow{2}{*}{ Tipo } & \multirow{2}{*}{ Id. } & \multicolumn{2}{|c|}{ Valores hipotéticos } \\
\hline & & RRA & CV \\
\hline \multirow{11}{*}{ 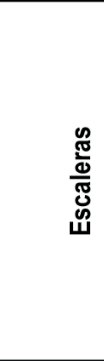 } & 1 & 1.043 & 0.41 \\
\hline & 2 & 1.043 & 2.25 \\
\hline & 9 & 1.391 & 1.53 \\
\hline & 11 & 1.304 & 1.03 \\
\hline & 14 & 1.565 & 0.66 \\
\hline & 19 & 1.826 & 2.33 \\
\hline & 28 & 1.217 & 1.08 \\
\hline & 32 & 1.217 & 1.37 \\
\hline & 46 & 1.565 & 0.83 \\
\hline & Media & 1.331 & \\
\hline & Desv. Est. & 0.261 & \\
\hline \multirow{6}{*}{ 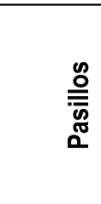 } & 4 & 1.130 & 0.45 \\
\hline & 17 & 2.087 & 1.33 \\
\hline & 37 & 1.565 & 0.66 \\
\hline & 59 & 1.304 & 0.62 \\
\hline & Media & 1.481 & \\
\hline & Desv. Est. & 0.417 & \\
\hline \multirow{7}{*}{$\frac{\text { o. }}{\stackrel{0}{0}}$} & 8 Patio sur & 1.130 & 1.75 \\
\hline & 34 Patio norte & 1.217 & 2.66 \\
\hline & 55 Alcazarejo & 1.565 & 1.83 \\
\hline & & 1.304 & 0.95 \\
\hline & 57 Liza & 1.043 & 5.16 \\
\hline & Media & 1.240 & \\
\hline & Desv. Est. & 0.200 & \\
\hline \multirow{16}{*}{ 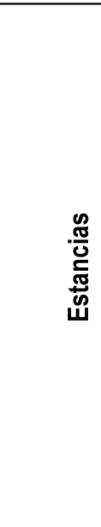 } & 3 & 1.043 & 1.78 \\
\hline & 5 & 1.304 & 0.25 \\
\hline & 6 Salón & 1.130 & 2.41 \\
\hline & 7 & 1.304 & 0.25 \\
\hline & 10 & 1.391 & 0.20 \\
\hline & 12 & 1.652 & 0.33 \\
\hline & 13 & 1.565 & 1.00 \\
\hline & 20 & 2.087 & 0.33 \\
\hline & 22 & 1.565 & 1.33 \\
\hline & 23 & 1.826 & 1.33 \\
\hline & 24 & 2.174 & 0.50 \\
\hline & 39 Sacristía & 2.087 & 0.33 \\
\hline & 49 & 1.826 & 1.33 \\
\hline & 50 & 2.174 & 0.50 \\
\hline & Media & 1.608 & \\
\hline & Desv. Est. & 0.387 & \\
\hline
\end{tabular}

\begin{tabular}{|c|c|c|c|}
\hline \multirow{2}{*}{ Tipo } & \multirow{2}{*}{ Id. } & \multicolumn{2}{|c|}{ Valores hipotéticos } \\
\hline & & RRA & CV \\
\hline \multirow{17}{*}{ 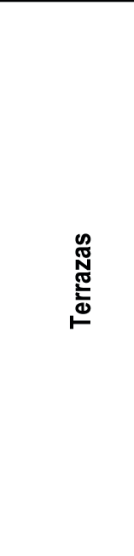 } & 16 Torre (norte) & 1.826 & 1.33 \\
\hline & 18 Torre (sur) & 2.348 & 0.50 \\
\hline & 21 Torre (central) & 2.087 & 0.33 \\
\hline & 27 Balcón amatacanado & 1.217 & 0.83 \\
\hline & 42 & 1.739 & 0.16 \\
\hline & 43 & 1.739 & 0.16 \\
\hline & 44 & 1.739 & 0.16 \\
\hline & 45 & 1.739 & 0.16 \\
\hline & 52 Balcón amatacanado & 1.391 & 2.50 \\
\hline & 53 & 1.739 & 0.25 \\
\hline & 54 & 1.739 & 0.25 \\
\hline & 65 & 1.304 & 0.16 \\
\hline & 66 & 1.304 & 0.16 \\
\hline & 67 & 1.304 & 0.16 \\
\hline & 68 & 1.304 & 0.16 \\
\hline & Media & 1.605 & \\
\hline & Desv. Est. & 0.326 & \\
\hline \multirow{12}{*}{ 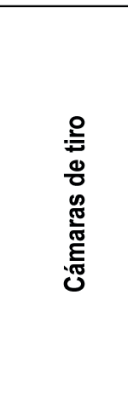 } & 25 & 1.391 & 0.33 \\
\hline & 26 & 1.217 & 0.83 \\
\hline & 33 & 1.478 & 0.33 \\
\hline & 35 & 1.565 & 0.25 \\
\hline & 36 & 1.565 & 0.25 \\
\hline & 47 & 1.304 & 0.62 \\
\hline & 60 & 1.826 & 0.33 \\
\hline & 61 & 1.391 & 0.12 \\
\hline & 62 & 1.391 & 0.12 \\
\hline & 63 & 1.391 & 0.12 \\
\hline & Media & 1.444 & \\
\hline & Desv. Est. & 0.169 & \\
\hline \multirow{6}{*}{ 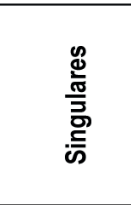 } & 38 lglesia & 1.826 & 2.00 \\
\hline & 41 Adarve del "enforrado" & 1.391 & 4.58 \\
\hline & 51 Adarve intermedio & 1.217 & 0.75 \\
\hline & 58 Espacio indeterminado & 1.043 & 0.29 \\
\hline & 64 Adarve de la falsabraga & 1.043 & 5.00 \\
\hline & $0^{\mathrm{b}}$ Exterior & 1.565 & 0.83 \\
\hline \multirow{5}{*}{$\begin{array}{l}\text { TOTAL } \\
\text { EDIFICIO }\end{array}$} & Minimo & 1.043 & \\
\hline & Media (sin exterior) & 1.469 & \\
\hline & Media (con exterior) & 1.493 & \\
\hline & Máximo & 2.348 & \\
\hline & Desv. Est. (sin exterior) & 0.330 & \\
\hline
\end{tabular}

Figura 14. Tabla de valores sintácticos del total hipotético del conjunto arquitectónico en su última gran fase constructiva; los datos primarios (RA y CV) se obtuvieron mediante el software Agraph 3.0 para el dibujo y cálculo de grafos de nodos y axiales en sintaxis espacial desarrollado por Bendik Manum, Espen Rusted y Paul Benze [https://www.ntnu.no/ab/spacesyntax consultado el 01/04/2020].

los cuales se sabe que carecieron de tal función quedan igual o incluso se tornan más integrados al incluirlo".

Pero dejando en suspenso lo que este indicio aporta para empezar a extraer conclusiones sobre el castillo de Turégano, lo primero que salta a la vista recorriendo su liza es la potencia sedimentaria que acumula, y, por consiguiente, la cantidad de información arqueológica todavía desconocida. Aun así, en el alzado de sus paramentos internos pueden observarse con claridad las huellas de hasta tres compartimentaciones hoy desaparecidas, dos de las cuales se reflejan a su vez en el edificio principal, lo que revela una complejización del acceso a un recinto que contaría con dos entradas jerárquicamente diferenciadas en la forma -y el significadode los espacios que las suceden: tras la noroeste sigue un pasillo cubierto en esviaje que aparece como un espacio relativamente controlado pero integrado, mientras que la proyección lineal de los muros perdidos al sureste dibujan una especie de alcazarejo, relativamente controlador pero más segregado. Tales cifras se explican dado que el primero desemboca directamente en la liza, que abrazaría el edificio por tres lados dando acceso tanto a la mayoría de cubos como al resto del castillo desde los vanos abiertos en altura $-\mathrm{y}$ desenfilados respecto a la entrada- en los espacios 47 y 31 , algo que le otorga el mayor valor de control del conjunto y una de las menores asimetrías relativas. Por su parte, el alcazarejo daría paso a un segundo patio centrado en la entrada de la iglesia y separado del resto de liza por un muro diafragma al occidente, en principio sin evidencias de umbral 
alguno, mientras que al oriente las huellas de quicios y trabas en la base de la torre del homenaje testimonian la presencia de otro vano. Determinar a dónde conducía esa tercera conexión resulta clave para el modelo en la medida en que pudiera guardar relación, a su vez, con el acceso original a la torre a través del espacio 1 , justamente encima de dichas huellas.

Las posibles respuestas a esta última cuestión son de nuevo múltiples; desde que se hubiera accedido a un sistema de escaleras acodadas prefigurando lo que se encuentra ya dentro de la torre sur, hasta que no hubiera habido variaciones en la posición de la escalera conservada hoy día, comunicando entonces dicho vano los espacios 56 y 57 directamente. Esta es de hecho la opción contemplada en el Plan Director del Castillo de Turégano, aunque no puede pasarse por alto ni que el desarrollo del patín actual bloquearía dicho vano, ni que, de hecho, su presencia pudiera estar enmascarando en parte otras posibles huellas en la base de la torre -por ejemplo, de haber existido alguna especie de corredor intermedio-.

La solución más sencilla tanto arquitectónica como sintácticamente se halla quizá en el mismo muro que cierra el alcazarejo por el norte, donde la impronta de un umbral más pequeño que los anteriores y precedido de escalones no parece llegar a atravesar su espesor. Y se trataría de la solución más sencilla porque permite resolver, con la inclusión de un único nodo hipotético, tanto el acceso a la torre del homenaje como al adarve que perimetraría, uniéndolos, la falsabraga y el alcazarejo, todos a la sazón a la misma cota. Ese adarve se perfilaría entonces como otro punto cardinal en el sistema circulatorio, matemáticamente equiparable a la liza a pesar de su mayor profundidad. De hecho, llegaría a superarla en valor de control en el supuesto de que dicho espacio indeterminado hubiera articulado directamente la comunicación entre patio y adarve sin pasar por la liza, lo cual hay que descartar por coherencia con lo aplicado en otras partes del edificio, pero se aproximaría bastante también al resultado obtenido en caso de segmentar esta última en términos perceptivos (Fig. 15).

Existe finalmente un nivel inferior en el interior del cubo suroeste que se ha excluido del análisis sintáctico. En la actualidad se accede desde el exterior gracias al ensanchamiento de una tronera abierta al sur, si bien anteriormente contó con un postigo en dirección contraria, sobre el foso, que pudo haberse cegado a raíz de la construcción de la coracha que une la falsabraga con la única torre circular de la cerca exterior, habilitando una explanada al sur que se ha fechado a partir del s. XVI (vid. nota 2). La cuestión es que toda posibilidad de comunicación vertical pasaría por el empleo de escalas a través de una buhedera. Y a decir verdad, sobre transferir parte del valor de control de la liza a un exterior así aún menos integrado, la consideración de ese dudoso y en cualquier caso precario tercer acceso tampoco variaría sustancialmente la sintaxis del resto del edificio, ninguno de cuyos índices globales variaría siquiera una centésima.

\section{UN ANÁLISIS MODIFICADO IDEALMENTE}

Sea como fuere, volviendo a la interpretación del grafo que resulta de este modelado hipotético (Fig. 16), parece funcionalmente coherente que una de las dos entradas contempladas fuera de toda duda en el proyecto original facilitara la circulación cotidiana ofreciendo un acceso rápido a los principales espacios distribuidores, como sería el caso de la noroeste. Máxime cuando esa ruta aparece jalonada de trabas en previsión de una eventual penetración hostil; y no solo el pasillo 59 queda física y significativamente controlado, sino que la única conexión entre la liza y el edificio principal que no requeriría de dispositivos móviles se ubica en el extremo opuesto, a través de la escalera que anuncia el umbral de 58.

La puerta sureste contaría asimismo con una construcción defensiva tan potente como el alcazarejo. Pero precisamente en esa potencia, que no minimiza su valor de control efectivo, pero sí pauta un espaciamiento del ingreso al edificio, se advierte oculta una lógica diferente a la militar: la de la expresión material del poder. No por nada, es evidente que la iglesia continuó jugando un papel muy activo en la teatralización discursiva de los vínculos transcendentes que definían aquella sociedad; $\mathrm{y}$ es precisamente el poder de la Iglesia lo que se pretende manifestar, no discursivamente, a lo largo de la ruta que conducía alternativamente hasta el salón y las estancias de recepción más privadas. La prominencia visual de la portada, protagonista absoluta del espacio 56 merced a la "remonumentalización" que supone su flanqueo por los borjes sureste y sur, y su relación con lo registrado en las simulaciones del movimiento ejecutadas desde ambas entradas dan buena cuenta de ello. Porque, aunque no implique necesariamente una merma en su "defensibilidad", existe amplio consenso en que la definición del concepto mismo de "castillo" no depende 


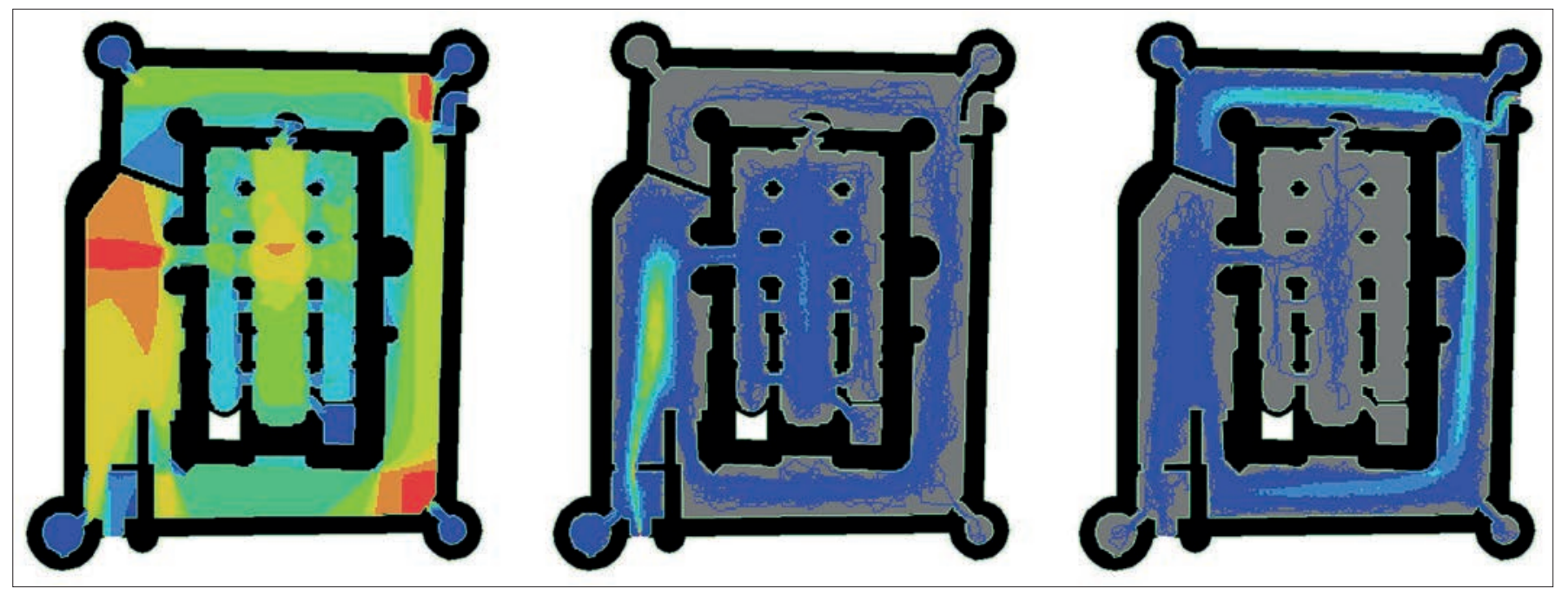

Figura 15. Grafo de visibilidad (VGA) del nivel 1 restituido hipotéticamente (izquierda) y análisis agente según los parámetros estándar de DepthMap X para una duración de 5000 timesteps con 50 agentes lanzados respectivamente desde las puertas sureste (centro) y noroeste (derecha).

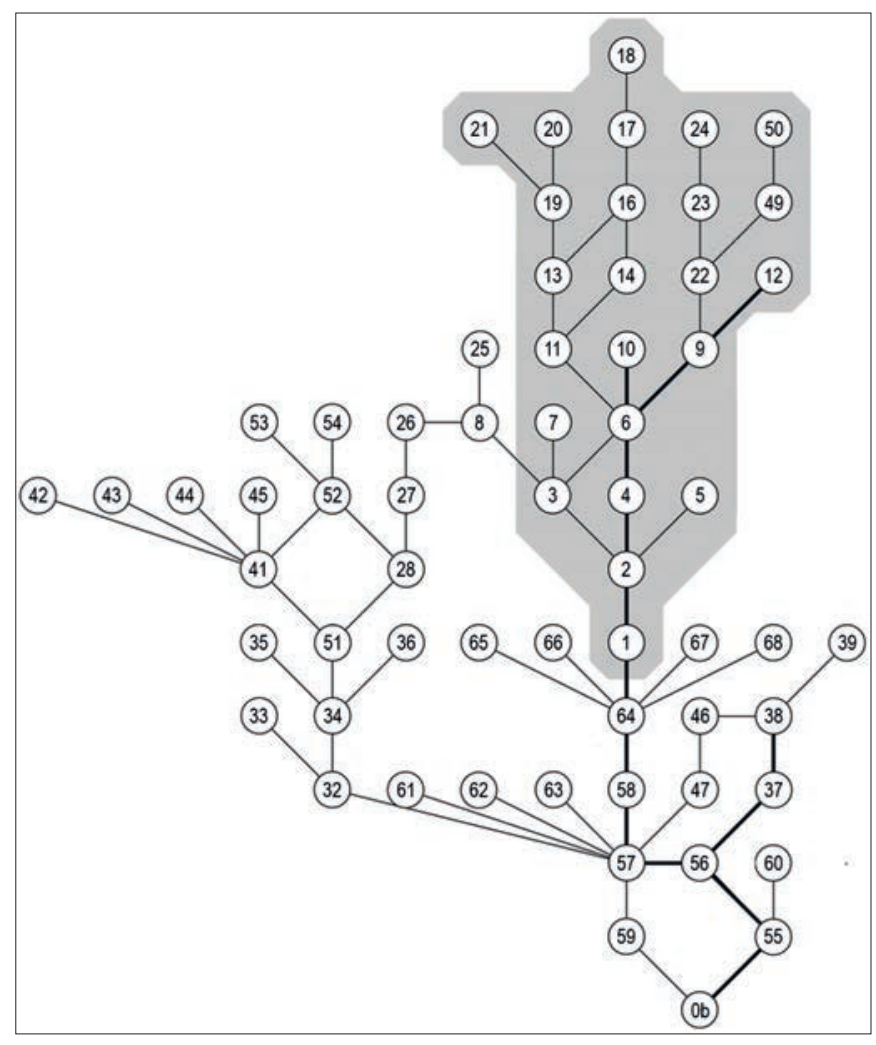

Figura 16. Grafo justificado del total hipotético del conjunto arquitectónico en su última gran fase constructiva, destacando en sombreado los espacios correspondientes a la torre del homenaje, así como el "eje de honor", que se extiende desde el exterior hasta la iglesia (38), el salón (6) y las estancias con chimenea en las torres sur y norte (respectivamente 10 y 12 ).

tanto de la función militar como de su concurrencia indisoluble con otras tantas funciones que vienen a redundar en la dimensión significativa de estos edificios; en la construcción de la identidad social de quienes los habitan y poseen (Varela 1999; Creighton y Liddiard 2008; Predovnik 2014).

En este sentido, no es sorprendente que la comparación de la asimetría relativa media del castillo de Turégano con los resultados obtenidos por Mol en su estudio de referencia lo aproximen antes al genotipo aristocrático (MRRA 1.647) que al de órdenes religiosas (MRRA 1.100), aun cuando el análisis modificado idealmente devuelve un edificio más integrado que el actual -y lo que no deja de ser curioso: compuesto por espacios estadísticamente más agrupados, a juzgar del descenso de la desviación estándar en general y en casi todas las categorías formales-. Tal característica también se refleja en el aumento de la circularidad de un sistema que suma cierta cantidad de anillos a los ya descritos para la torre del homenaje, la mayoría de los cuales pivotan en el espacio 57 de liza: el que conlleva de suyo la existencia de dos entradas cotidianas al recinto; el que desde aquí se establece con la iglesia como punto distal, conformando dos rutas matemática pero desde luego no significativamente idénticas; y el más largo de todos con diferencia, que atraviesa el edificio por los niveles 2 y 3 reuniendo tras de sí la práctica totalidad de espacios con menores índices de asimetría relativa y englobando, a su vez, el dispositivo que articula la comunicación con las terrazas de los borjes, entre los espacios 41-52. Al margen de ese anillo, solo el salón y el pasillo que le precede presentan cifras más bajas que sus máximas, pero tampoco llegan a equipararse con sus mínimas. En cualquier caso, en su momento quedó claro ya que estos 
dos espacios en concreto no estarían tan enfocados a las necesidades de circulación interna como a la segregación de los visitantes en términos del control de la privacidad y su representación. Y ahora, puesto todo junto, una comprensión ciertamente hipotética pero también más acabada de los rasgos constitutivos básicos de esa circulación empuja quizá a reconsiderar globalmente la cuestión de la utilidad militar.

El hecho de que, ante los problemas planteados por las en ocasiones muy escurridizas modificaciones ulteriores, las soluciones relativamente conservadoras, que requerían poner en juego menos incógnitas, hayan maximizado incidentalmente la capacidad defensiva del edificio mediante su compartimentación en profundidad escalonada parece algo más que una casualidad. Ejemplos claros de esto son el que no se encuentren argumentos suficientes para sostener que la rotura del macizado del campanario y la consiguiente comunicación a través de las escaleras 15-31 formaran parte del proyecto original; o como ya he señalado, que las puertas abiertas sobre la liza obliguen siempre a realizar el recorrido más largo -y más expuesto- posible desde la entrada al recinto fortificado por el noroeste. Otro tanto sucedería una vez se accede a las cubiertas de la iglesia, donde todo paso hacia la torre del homenaje por el norte se ha condenado y no parece haberse facilitado otro camino hacia el sur transitando los adarves por el extremo occidental, a la sazón la parte que más cómodamente baten las terrazas de la torre. Incluso aquí, la disminución del valor de control que implica para el patio 8 la ausencia de conexión directa con esos adarves -desde luego posible, pero en las circunstancias actuales del registro, no probable- cabe dentro de esta lógica y se conjuga con el hecho de que el espacio más profundo sea precisamente la terraza de la torre sur, que dispuesta sobre ellos, cubre mejor que la central tanto este como el acceso por el espacio 1. Porque en efecto, llegados a tal extremo, los mismos rastrillos a ambos lados del pasillo 17 que protegen la meridional, obligan a tomar primero esta otra terraza más alta, y eso supone que también se ha tenido que tomar previamente todo el resto del edificio.

Con independencia de la sintaxis, al introducir el caso de estudio avanzaba que las características formales de esta fortificación cuadran perfectamente con las primeras respuestas a la guerra artillera. Es cierto, de un lado, que más allá de la eventual inconclusión de algunas partes, el castillo de Turégano presenta problemas tácticos tan potencialmente graves como la ausencia de bocas de tiro capaces de barrer un foso de escarpa aparentemente vertical; o la falta, de nuevo aparentemente, bien de una adecuación tecnológica de la cerca exterior o bien de su desmantelamiento total. Pero tampoco puede olvidarse no solo que adaptaciones igual o más limitadas siguieron edificándose en la Península Ibérica hasta bien entrado el s. XVI (Ivars 2013; Bevià et al. 2017), sino que a diferencia de Francia, la paulatina implementación de las armas de fuego se abordó en los reinos peninsulares centrándose estratégicamente primero en las piezas de pequeño calibre (Cobos y Castro 2000). O, en fin, olvidar que como escribió Luis de Mora-Figueroa (1996: 24-25), "la práctica había de demostrar que con frecuencia resultaba precipitado deducir fácil expugnabilidad de las viejas fortalezas" (vid. Palomino et al. 2012); deducir, dicho de otro modo, la inutilidad funcional, incluso la inutilidad pretendida, de la existencia de limitaciones.

\section{APENAS DOS IDEAS, EN CONCLUSIÓN}

Es evidente que queda todavía mucho por hacer -afortunadamente- tanto en este caso de estudio como, en general, en la aplicación analítica de la sintaxis espacial a la Castellología española. Quizá a partir de este punto puedan empezar a vislumbrarse algunas cuestiones por donde continuar una exploración que, sin duda, requiere aumentar ahora la base comparativa, habida cuenta del potencial que en ese sentido demuestran este tipo de herramientas para la interpretación del espacio construido; en especial cuando se integran con otro tipo de aproximaciones, que en Arqueología pasan necesariamente por una perspectiva diacrónica. De hecho, opino que ensayos como el aquí propuesto constatan que ese potencial es también dinámico. Que, aplicado experimentalmente, un enfoque sintáctico es capaz de coadyuvar de forma determinante a desentrañar, tanto como a interpretar, esa diacronicidad.

Por el momento, todo lo dicho aquí apunta a una explicación de la última gran fase constructiva de la iglesia encastillada de San Miguel de Turégano ciertamente marcada por la representación señorial, pero no por ello menos adecuada a los estándares poliorcéticos del momento preciso en que se proyectó; puede que en respuesta a una urgencia más o menos acuciante que a una política episcopal a largo plazo; y puede que por eso, superado lo inmediato, careciera en efecto de todo sentido llevar las cosas más allá de unos signos formales que tampoco tardarían demasiado en quedar 
culturalmente obsoletos. Lentamente devueltos entre reformas, abandonos y restauraciones a los interminables procesos de resignificación de un paisaje que participa de la adaptación evolutiva de nuestras culturas. Que es producto y produce, ahora, otras identidades sociales muy distintas.

\section{AGRADECIMIENTOS}

Además de a los compañeros involucrados en los trabajos llevados a cabo sobre el castillo de Turégano, ya mencionados en la primera nota al pie, he de agradecer el apoyo e interés mostrado en todo momento por Rocío Martín Bonet y Jesús Bravo Solana, así como por Manuel de la Peña Borreguero y Silvia Olmos Arranz. Los comentarios de Jesús Bermejo Tirado, que leyó un primer borrador del texto, fueron -como siempreinestimables. Quisiera, finalmente, hacer extensivo mi agradecimiento de manera especial en esta ocasión a Sonia Gutiérrez Lloret, a quien debía, y seguramente aún debo, mucha más Edad Media.

\section{BIBLIOGRAFÍA}

Arrieta Berdasco, V. 2012: "Avance de estudios sobre la arquitectura de las iglesias fortificadas de Castilla y León", en A. Ruibal Rodríguez (coord.), Actas del IV Congreso de Castellología, pp. 223-229. Asociación Española de Amigos de los Castillos, Madrid.

Bafta, S. 2003: "Space syntax: A brief introduction to its logic and analytical techniques", Environment and Behavior, 35 (1), pp. 17-29. https://doi. org/10.1177/0013916502238863

Bango Torviso, I. G. 1997-1998: "El verdadero significado del aspecto de los edificios: De lo simbólico a la realidad funcional, la iglesia encastillada", Anuario del Departamento de Historia y Teoría del Arte, 9-10, pp. 53-72.

Bermejo Tirado, J. 2009: "Leyendo los espacios: Una aproximación crítica a la sintaxis espacial como herramienta de análisis arqueológico", Arqueología de la Arquitectura, 6, pp. 47-62. https://doi.org/10.3989/ arqarqt.2009.09004

Bermejo Tirado, J. 2014: Arqueología biopolitica: La sintaxis espacial de la arquitectura doméstica romana en la Meseta oriental. La Ergástula, Madrid.

Bermejo Tirado, J. 2015: "Aplicaciones de sintaxis espacial en Arqueología: Una revisión de algunas tendencias actuales", Arqueología de la Arquitectura, 12: e031. http://dx.doi.org/10.3989/arq.arqt.2015.122

Bermúdez Medel, A. y Marqués Martín, I. 2016: “Análisis arqueológico de la arquitectura del castillo de Turégano (Segovia, España)”, Oppidum, 12, pp. 245-276.

Bevià i Garcia, M., Mira Rico, J. A., Ortega Pérez, J. R., Baldaquí Escandell, R. y Yáñez Martínez, M. B. 2017: "La Torre Grossa del Castell de Castalla (Alicante, España): Un ejemplo primerizo de arquitectura pre-abaluartada en el sur del Reino de Valencia”, en A. B. González Avilés (ed.), Defensive architecture of the Mediterranean, XV to XVIII Centuries, vol. 6, pp. $107-$ 114. Publicacions Universitat d'Alacant, Alicante.

Borreguero Vírseda, V. 1991: El señorio episcopal de Turégano. Caja de Ahorros de Segovia, Toledo.
Bourdieu, P. 2008: El sentido práctico. Siglo XXI, Madrid.

Bourdieu, P. 2012: Bosquejo de una teoría de la práctica. Prometeo, Buenos Aires.

Centeno Roldán, P. 1974: Turégano y su castillo en la iglesia de San Miguel: Estudio crítico de su historia y arquitectura. Diputación Provincial, Segovia.

Cobos Guerra, F. y Castro Fernández, J. J. 1990: "Los castillos señoriales de la Escuela de Valladolid", en P. Navascués Palacio y J. L. Gutiérrez Robledo (eds.), Medievalismo y neomedievalismo en la arquitectura española: Aspectos generales, pp. 147-164. Universidad de Salamanca, Ávila.

Cobos Guerra, F. y Castro Fernández, J. J. 2000: «Artillería y poliorcética castellana en la estrategia de Fernando el Católico contra Francia: Documentos para su estudio», Gladius, 20: 251-268. https://doi.org/10.3989/ gladius.2000.73

Creighton, O. y Liddiard, R. 2008: "Fighting yesterday's battles: Beyond war or status in Castle Studies”, Medieval Archaeology, 52 (1), pp. 161-169. https://doi.org/10.1179/174581708x335477

Dimanuel Jiménez, M. 2009: "La investigación de la arquitectura religiosa fortificada medieval española: Estado de la cuestión y metodología", Anales de Historia del Arte, extra 1, pp. 295-308.

Fairclough, G. 1992: "Meaningful constructions: Spatial and functional analysis of medieval buildings", Antiquity, 66, pp. 348-366. https://doi. org/10.1017/s0003598x00081461

Geertz, C. 2005: La interpretación de las culturas. Gedisa, Barcelona.

Grau Mira, I. y Segura Martí, J. M. 2013: “Estructuras domésticas y organización del espacio", en I. Grau Mira y J. M. Segura Martí (eds.), El oppidum ibérico de el Puig d'Alcoi: Asentamiento y paisaje en las montañas de la Contestania, pp. 169-194. Ayuntamiento de Alcoi, Alcoi.

Gutiérrez Lloret, S., 2012: “Gramática de la casa: Perspectivas de análisis arqueológico de los espacios domésticos medievales en la Península Ibérica (ss. VII-XIII)", Arqueología de la Arquitectura, 9, pp. 139-164. https://doi. org/10.3989/arqarqt.2012.11602

Gutiérrez Lloret, S. y Grau Mira, I. (eds.) 2013: De la estructura doméstica a la vida social: Lecturas arqueológicas del uso social del espacio. Publicaciones de la Universidad de Alicante, San Vicente del Raspeig.

Hall, E. T. 1990: The silent language. Anchor Books, New York.

Hall, E. T. 2003: La dimensión oculta. Siglo XXI, México D. F.

Hanson, J. 2003: Decoding homes and houses. Cambridge University Press, Cambridge.

Hillier, B. 2007: Space is the machine: A configurational theory of architecture. Space Syntax, London.

Hillier, B. y Hanson, J. 1984: The social logic of space. Cambridge University Press, Cambridge.

Hodder, I. 2012: Entangled: An archaeology of the relationships between humans and things. Wiley-Blackwell, Oxford.

Ivars Pérez, J. 2013: “Intervenció a la Torre de la Comare: Palau dels Centelles", Cabdells, 11, pp. 5-17.

López Lillo, J. A. 2019: La politica salvaje: Una teoría genealógica de los fundamentos sociales. BAR Publishing, Oxford.

López Lillo, J. A. y Yuste Burgos, L. M. (en prensa): "La iglesia encastillada de San Miguel de Turégano (Segovia): Avance de los trabajos de Arqueología de la Arquitectura", en Actas del VI Congreso de Arqueología Medieval (España-Portugal).

Mañana Borrazás, P., Blanco Rotea, R. y Ayán Vila, X. M. 2002: Arqueotectura 1: Bases teórico-metodológicas para una Arqueología de la arquitectura. Laboratorio de Patrimonio, Paleoambiente e Paisaxe, Santiago de Compostela.

Mol, E. 2012: Hidden complexities of the Frankish castle: Social aspects of space in the configurational architecture of Frankish castles in the Holy Land, 1099-1291. Leiden University Press, Leiden.

Mora-Figueroa, L. 1993: "Fortificaciones de transición: Del castillo al fuerte abaluartado", en E. Cruces Blanco (coord.), La organización militar en los siglos XV y XVI: Actas de las II Jornadas Nacionales de Historia Militar, pp. 399-411. Cátedra "General Castaños", Málaga.

Mora-Figueroa, L. 1996: Glosario de arquitectura defensiva medieval. Universidad de Cádiz, Cádiz. 
Moreno Martín, F. J. y Murillo Fragero, J. I. 2014: "Secuencia constructiva de la iglesia de Nuestra Señora de Campanario en Almazán (Soria): Datos para la interpretación de sus estructuras románicas", Arqueología de la Arquitectura, 11: e020. http://doi.org/10.3989/arq.arqt.2014.174

Olsen, B. 2010: In defense of things: Archaeology and the ontology of objects. Altamira Press, Lanham.

Palomino, A. L., Moratinos, M., Gonzalo, J. M., Santamaría, J. E. y Centeno, I. M. 2012: "Villalonso: Un castillo medieval en la transición hacia la modernidad", en A. Teixeira y J. A. Bettencourt (coords.), Velhos e novos mundos: Estudos de arqueologia moderna, vol. 1, pp. 393-406. Centro de História de Além-Mar, Lisboa

Penn, A. y Turner, A. 2002: "Space syntax based agent simulation", en M. Schreckenberg y S. D. Sharma (eds.), Pedestrian and evacuation dynamics, pp. 99-114. Springer, Heidelberg.

Predovnik, K. 2014: "The castle as social space: An introduction", en K. Predovnik (ed.): The castle as social space, Castrum Bene 12, pp. 13-21. Ljubljana University Press, Ljubljana.

Preucel, R. W. 2010: Archaeological semiotics. Wiley-Blackwell, Oxford.

Rapoport, A. 1990: The meaning of the built environment: A nonverbal communication approach. The University of Arizona Press, Tucson.

Rapoport, A. 1993: "Systems of activities and systems of settings", en S. Kent (ed.), Domestic architecture and the use of space: An interdisciplinary cross-cultural study, pp. 9-20. Cambridge University Press, Cambridge.

Richardson, A. 2003: "Corridors of power: A case study in access analysis from medieval England", Antiquity, 77, pp. 373-384. https://doi. org/10.1017/s0003598x00092358

Rodríguez Montañés, J. M. 2007: "Turégano: Iglesia de San Miguel Arcángel”, en Enciclopedia del Románico: Segovia, vol. 3, pp. 1752-1764. Fundación Santa María la Real, Aguilar de Campoo.
Ruiz Montejo, I. 1988: El románico de villas y tierras de Segovia. Encuentro, Madrid.

Sahlins, M. 2008: Islas de historia: La muerte del capitán Cook; metáfora, antropología e historia. Gedisa, Barcelona.

Salminci, P. 2015: "Simetría y diferenciación espacial: Los edificios de La Alumbrera, Antofagasta de la Sierra”, Arqueología, 21 (1), pp. 89-114.

Sánchez, J. 1998: "La arqueología de la arquitectura: Aplicación de nuevos modelos de análisis a estructuras de la Alta Andalucía en época ibérica", Trabajos de Prehistoria, 55 (2), pp. 89-109. https://doi.org/10.3989/ tp.1998.v55.i2.305

Turner, A., Doxa, M., O'Sullivan, D. y Penn, A. 2001: "From isovists to visibility graphs: A methodology for the analysis of architectural space", Environment and Planning B, 28, pp. 103-121. https://doi.org/10.1068/ b2684

Turner, A. y Penn, A. 2002: "Encoding natural movement as an agent-based system: An investigation into human pedestrian behaviour in the built environment", Environment and Planning B, 29, pp. 473-490. https://doi. org/10.1068/b12850

Vaquer, J. M. y Nielsen, A. E. 2011: “Cruz Vinto desde la superficie: Alcances y limitaciones de la sintaxis espacial en un sitio del Periodo de Desarrollos Regionales Tardío (ca. 1200-1450 d. C.) en el Norte de Lípez, Potosí, Bolivia”, Revista Española de Antropología Americana, 41 (2), pp. 303-326.

Varela Agüí, E. 1999: "Fortificación medieval y simbolismo: Algunas consideraciones metodológicas", Medievalismo, 9, pp. 41-62.

Yuste Burgos, L. M. 2017: "La iglesia encastillada de San Miguel Arcángel de Turégano (Segovia, España): Estado de la cuestión”, Cuadernos de Arquitectura y Fortificación, 4, pp. 105-132. 